\title{
122nd Anniversary MBAA Convention Abstracts of Oral and Poster Presentations
}

\section{Oral Presentations}

\author{
0-1 \\ Intelligent process technology-A change of paradigm in \\ brewing \\ Presenter: Jens Voigt, Technische Universität München, \\ Weihenstephan, Germany \\ Coauthor(s): Hans Scheuren and Karl Sommer, Technische \\ Universität München, Weihenstephan, Germany; Hans-Jörg \\ Menger, Ziemann Ludwigsburg GmbH, Ludwigsburg, \\ Germany
}

The efficiency of the brewing process has been greatly improved by mechanical and process design and automation. While individual product qualities are required independently from design and technology, the raw materials input and changing qualities of raw materials require enormous flexibility by brewers in adapting their production recipes. Ensuring a defined quality is limited by the plant utilized, the operation process, time, and utilities. This paper describes old and new efforts to create intelligent process control tools to direct the brewing process. Tools for optimization have been introduced for specific smaller areas like lauter tun performance. Also, in packaging the development of intelligent operation control units is ongoing. The current work, which is part of a scientific project combining the efforts of brewing technology, systems process technology, and general process technology, implies control of the mashing process. The main target is the development of a model-based tool for control that will be used instead of standardized mashing regimes that refer to temperature and time only. The model-based tool will be used to maximize use of the raw materials and lead to best utilization of the plant, while saving time and energy. This also makes new sensitive measuring necessary. The model is being developed from enzyme reactions that are derived from the formulation of kinetic mass conversion formulae and mass transfer coefficients. With this, a prediction of the performance of the mashing procedure also becomes feasible. Once this methodology is developed, similar activities can be adapted for other bioprocess areas in brewing and similar industries, e.g., fermentation performance can be controlled in a similar manner. The target of this methodology is better utilization of raw materials, faster performance, and better use of the existing plant. Because experience and expert knowledge is used and transferred into model-based applications, this is a true change in brewing philosophy. The prediction of product quality parameters allows individual product characterization. The project is supported by major suppliers of the brewing industry and the scientific support organization of the German Brewers Association.

Jens Voigt received a diploma engineer (M.S.) degree in brewing and beverage technology from TU MünchenWeihenstephan in 1985. He started his career with A. Steinecker GmbH, Freising, Germany, as a technical engineer in brewhouse and fermentation and filtration equipment. He held sales and product and manager positions with Steinecker until 1995. From 1988 to 1992 he worked on his doctorate in brewing technology on beer foam from Weihenstephan (Professor Narziß). In 1996 he joined Doemens Brewing School in Munich, Germany, as managing director. In late 1997 he joined Heinrich Huppmann GmbH, Kitzingen, Germany, as key account manager for brewery equipment and was managing director of brewmaxx, a supplier of software solutions for the brewing industry. Since early 2004 he has been a research associate with Professor Karl Sommer at Lehrstuhl für Maschinen- und Apparatekunde (Chair for Mechanical Engineering and Process Technology) at the WZW (Wissenschaftszentrum Weihenstephan), Center of Life Science, Weihenstephan, Germany, working on brewing process technology issues. He is a member of the MBAA and IBD, the editorial board of the Journal of the Institute of Brewing, London (JIB), and the MBAA Global Emerging Issues Committee. His work group was recently awarded the EON Award for environment.

\section{O-2}

Behavior of miscellaneous aroma substances of malt and hops under different conditions during wort boiling Presenter: Udo Kattein, Technische Universität München, Freising, Germany

Coauthor(s): Stefan Hanke and Sebastian Kappler, Technische Universität München, Freising, Germany

Over the last decades, a large pattern of flavor components derived from malt and hop has been determined in wort and beer. Many of these substances are aldehydes, resulting from fatty acid metabolism during malting or from Strecker degradation, as well as ketones and higher alcohols. As these substances have an influence on the flavor and a mostly negative impact on the flavor stability of beer, one goal of wort production should be to decrease their concentrations. With regard to this demand, the process of wort boiling is extremely important, as parts of these substances are removed through evaporation, while other compounds can be regenerated by high input rates of thermal energy. The facilities of the new research brewery introduced in Weihenstephan in 2005 permit a nearly boundless scope for investigations of this process. Different boiling systems (internal, external cooker, varioboil, and vacuum solutions (schoko)) have already been tested in several trials. Final technical installations now are suitable for collection of condensed vapors and rating of thermal energy input as well. New trials also are being performed with different kettle evaporation rates. Using internal and external heating systems with different piping solutions, as well as traditional heating with steam jackets and a vacuum solution, thermal energy input rates are quantified. This paper compares the different trials with regard to the results of analyses of volatile aroma substances in the finished worts, as well as some new findings on their influence on flavor stability.

Udo Kattein received a diploma engineer degree from the Technical University of Munich-Weihenstephan in 1972. Afterward, he performed an economic study at the University 
of Munich, receiving a diploma merchandiser degree in 1976. At this time he began his doctoral thesis and employment at TU Munich, where he was in charge of the technical leadership of the Trial and Research Brewery at Weihenstephan. He served as head brewer and was responsible for production of commercially sold malts and topfermented beers. In addition to these tasks, he was involved in the development of new beer types and training of students. In 1984 he received his Ph.D. degree in engineering scienceshis thesis was on the investigation of sulfur compounds in malt, wort, and beer. Since 2002 Udo has been responsible for the construction of the new malting and brewing facilities at the research brewery, which started up in 2005.

\section{0-3}

Practical brewhouse operations

Presenter: David Kapral, Brewing Consulting Services, Boise, ID

Brewhouse training has historically been a function of providing a basic education in equipment functionality and a considerable amount of biochemistry of malting, mashing, and kettle reactions. Integrating the concepts so that the process is mastered is left to brewhouse managers when they take on the role of control of the operation. The huge amount of variability in each plant's operation means this is easier said than done, and the learning curve can be steep. Regardless of inherent variability within a plant or between plants, there are basics that can help managers deal successfully with inconsistency! This paper seeks to integrate seemingly disparate and minimally related information in a constructive manner. It allows managers to pick and choose from available tools and techniques and to do so with a full understanding of the cause and effect of the actions chosen. The objective is to help brewhouse managers be the drivers of their process instead of the person who is driven by the process! This paper focuses on four key interrelated objectives. 1) Define the measureable parameters the brewhouse is actually responsible for as a consequence of operation. Three basic examples would be meeting RDF, IBU's, and color specifications. A fourth could be a capacity objective such as expected brews/day. 2) Examine the multiple, and sometimes unexpected, techniques for meeting each of the specific parameter objectives covered in the talk. 3) Rank the techniques on a 1-10 scale as to effectiveness in meeting the specific objective. 4) Integrate the information: develop a fully comprehensive view of what the brewhouse is responsible for and how to achieve it through procedures and equipment. The author has used and refined this approach to brewhouse processing operations over the years. In one particular case, he and his team increased brew size from 695 to $915 \mathrm{bbl}$, while increasing yield from 88.5 to $91.5 \%$ and simultaneously shortening the mash-in cycle from 155 to $144 \mathrm{~min}$; all with minimal investment in equipment. The work improved capacity, increased yield, and improved overall wort quality. In another example, the author was able to advance a flavor match project where a new brewhouse had to match the flavor from the "old side." The sources of flavor differences and lautering problems were successfully identified and improvements were made to flavor, lautering cycle times, and kettle operations.

David Kapral retired from his 35-year career at AnheuserBusch in 2003. He immediately began pursuing ways to contribute to the industry! David's career at $A-B$ provided unusual opportunities for growth, and he made a career of tackling these opportunities, including leading capacity expansions and handling complex process problems; leading modernizations; and assisting with development of cost systems. David's career finished on a high note, having been selected to lead the Baldwinsville modernization and automation project. Since retiring, he has formed a consulting company, Brewing Consulting Services. He has worked on projects in the craft brewing industry such as flavor-matching beer from a "new side" brewhouse to the preferred beer from the "old side," correcting stratification in fermenters, a dryhopping project, a capacity growth management project, and an entrepreneurial effort to start an African brewery. One of David's goals is to give back to the brewing industry. This has involved development of a group of lectures he refers to as the "Practical Brewing Series." To date it includes brewhouse operations, stratified fermentations, and project management. David has presented at four MBAA Conventions. His lecture on stratified fermentations was an Editor's Choice in the Technical Quarterly. David has also lectured at MBAA's packaging short course on the topic of practical brewhouse operations. David has been the keynote speaker at MBAA District Northwest and District Philadelphia technical conferences.

\section{O-4}

\section{Supplier quality-Continuous improvement tools for better results}

Presenter: Michelle Johnson, MillerCoors

Coauthor(s): Jay Chung, MillerCoors

Incoming packaging material quality is vital to a brewery's performance. The success of a brewery is dependant on the success of its suppliers, so they should be considered an extension of the brewery's family. This can be achieved by building a strong partnership and implementing a supplier "continuous improvement toolbox" that engages a supplier in the brewery's methodology for continuous improvement and develops their problem-solving skills. The toolbox provides proven techniques to systematically solve problems, eliminate variation, and reduce defects at the supplier's location. In turn, these improvements can help reduce brewery costs, increase performance, and eliminate waste. These efforts will also better equip suppliers to partner with brewery teams to drive results on the packaging floor. This presentation will discuss the advantages of incorporating the toolbox into your existing supplier quality management program.

Michelle Johnson has worked in the quality field for 10 years and has been with MillerCoors for 2 years as a senior quality engineer. Her primary focus is on improving incoming material quality and supplier partnerships. Michelle has received extensive training in problem-solving and continuousimprovement techniques. She received her degree from the University of Missouri-Columbia. 


\section{0-5}

The need for brewing process planning and execution Presenter: Peter Macwilliam, Flowmation Systems, Oakville, ON, Canada

Gartner Group maintains that "ignorance is the greatest threat to modern business" and "the risk of "not knowing' is immense." Yet the reality is that "not knowing" becomes the status quo in the brewhouse. Why? Most industry-standard ERP, planning, scheduling, and/or execution systems and enterprise software tools are targeted at the users of information, who are outside the brewhouse. Yet, the business decision makers who materially control what is available and when certain products will or can actually be ready, to address changing demand, are typically not well served by traditional systems. Thus, there is a substantial gap between what production-oriented management and staff need and what these applications and tools deliver (resulting in Gartner's "not knowing" issue). The impact is that brewers struggle to be flexible and to respond to changing demand, meet demand, and report on output, while trying to also easily view the health of the business. They juggle work to ensure a smooth, well-behaved supply chain (SC) to meet sales demand at target costs and specifications/flavor profiles but do not generally have integrated operational information and data, in real time, at their fingertips for a more detailed view of the operation. What they have for "tools" generally are informal systems of multiple spreadsheets, which are always wrong, out of date, not real time, not integrated, and not accurate, to support a well-behaved SC. Process controllers provide too much data, while traditional corporate ERP provides too little. At the initiative of Molson Breweries, a "bottom-up" strategy was launched to develop a solution to this problem. This presentation will highlight that solution, which is also currently used by Sleeman Breweries and Moosehead Breweries, who have benefited by driving to flavor profiles, increased capacity, reduced shrinkage, higher yields, and improved fermentation attenuation.

Peter A. Macwilliam is CPIM president and chief system architect for Flowmation Systems, specializing in information management systems for the beer and wine industries. Peter has a B.S. degree in computer science, post-graduate work in information management, and 35 years of application systems experience. He has American Production and Inventory Control Society certification and is a member of IEEE and ACM. Peter has designed systems and managed projects for commercial software vendors and been involved in the training and education of large groups of novice and literacychallenged users.

\section{O-6}

Global market quality assurance: Identifying opportunities to continuously improve product integrity

Presenter: Sakura Yanai, Cerveceria Nacional Dominicana, Santo Domingo, Dominican Republic

Quality assurance of beer is far more extensive than just working inside the production plant. In order to maintain customer satisfaction, it is necessary to assure product integrity through warehouse, handling, distribution, and commercial activities. This work details the methodology that Cervecería Nacional Dominicana (CND) uses to sustain and improve product and service quality in the market. All post- production stages are periodically inspected and audited to verify that materials, processes, technologies, environment, and human resources involved with the product meet the required standards. The main benefit of these efforts is a twoway feedback process that provides valuable information for the company's decision-making process, as well as improved client and customer awareness.

Sakura Yanai has been a member of the Cerveceria Nacional Dominicana (CND) production team since 1989, when she started as a chemist in the Quality Assurance Department. Sakura has held different roles at the brewery in the areas of quality assurance and research and development. In 2002 she became a manager and since 2007 has been special projects manager. She graduated from UNPHU College in Santo Domingo and Doemens School in Germany. She is also a professional taster and is in charge of the CND Professional Panel. Sakura is an active member of $M B A A$ and $A S B C$.

0-7

Passivation and validation methods in the modern brewery Presenter: Chad Thompson, Ecolab, Eagan, MN

Coauthor(s): Joe Dirksen, Ecolab, Shoreview, MN

Every brewery, no matter how big or small, uses stainless-steel equipment in the brewhouse and packaging hall. Likewise, every brewer has concerns regarding passivation of their stainless-steel equipment. Stainless steel is selected for various reasons, including corrosion resistance, chemical resistance, clean-ability, and length of service. With rising costs of stainless-steel equipment and an uncertain economy, brewers are interested in maintaining and protecting their investment now more than ever. This presentation will discuss the theory and science behind passivation. Included in this discussion is a review of best practices and the differences in published passivation methods. It will cover common pitfalls of passivation and how to avoid them. Validation methods are also covered, as this is always a hot topic among brewers. Finally, the presentation will outline two case studies with real-world applications and results.

Chad Thompson has combined his passion for brewing and his 15 years of packaging design and development experience by taking on the role of scientist in the Brewery \& Beverage Division of Ecolab USA. He has been brewing for 12 years and has been with Ecolab for 5 years. During his time at Ecolab, he has contributed to numerous business segments within the corporation. Chad received a degree from Michigan State University in packaging engineering and has been granted three patents for his work.

\section{O-8}

Advanced process analysis and data mining using hybrid simulation

Presenter: Martin Nagel, Technische Universität München, Freising, Germany

Coauthor(s): Antonio Delgado, Universität ErlangenNürnberg, Nürnberg, Germany

Data mining and other process analysis methods are widely used tools for knowledge extraction for process optimization, e.g., predicting beer filtration performance or the formation and decomposition of substances during the steps of brewing. 
Input data are mainly derived from in-house laboratory data or an MES database, thus the available data cover only the actual operational range of the respective brewery, e.g., brewing process. Assuming the investigated process is already running on an average optimization from medium to good performance, the data basis for further analysis using data mining is limited to that field of operation. As a result, relevant criteria or cluster parameters marking especially negative influences on the process are statistically underrepresented to sufficiently impact the data analysis. Obviously a real-life process cannot be run on substandard performance to obtain the missing data. At this point, hybrid simulation can be used to supplement the databases. The hybrid simulation environment was developed to resolve simulation problems through the coexistence of discrete-timed and continuoustimed process segments in bioprocess-engineering or brewing, i.e., by allowing, among other things, the combination of fuzzy logic and artificial neural networks, for example, for the modeling of different process steps. Finally resulting in a "virtual brewery," the simulation can be used to run "virtual" brewing under various conditions and constraints, obtaining additional data for further analysis. The so expanded dataset is subjected to established methods of data mining like decisions trees or em-clustering (expectation maximization clustering algorithms). The aim is not to search for optimization parameters for a special production set but to derive more generally valid parameters or "rule sets." Em-clustering in regard to frequency of triplets from batch sequences in production of different beer varieties, for example, could lead to the following rule sets: "producing an ale batch between two lagers is good for production time" or "producing your season specialty on Monday can lead to higher energy consumption." Preliminary tests in a medium-sized brewery, focusing on energy consumption, showed energy savings by implementing such rules in the range of 5-10\%. More accurate data can be provided after the end of the current production term. Another approach currently under investigation is feeding production and simulation data regarding production plans to an artificial neural to assess operational planning efficiency.

Martin Nagel was born in 1979. Martin is a research assistant at Information Technology Weihenstephan (ITW) of the Technische Universität München (TUM), specializing in process analysis, modeling, simulation, and optimization. His research was funded by a scholarship granted by the Weihenstephaner Jubiläumsstiftung 1905 until July 2006 and the Fleischmann Fonds of the TUM until July 2008. Additionally, he is organizing and giving classes in higher mathematics and information technology. He started working at the ITW in November 2004 directly after finishing his Dipl.Ing. degree studies in brewing science and beverage technologies.

\section{0-9}

The advantages of fieldbus technology for a brewery expansion project at a regional brewery

Presenter: Peter Koestler, The Gambrinus Company, San Antonio, TX

This presentation will show the advantages of modern fieldbus technology in brewery automation by comparing two expansion projects in a regional brewery one decade apart. In 1996, the Spoetzl Brewery in Shiner, TX, went through an expansion that added 18 1,100-bbl unitanks to the fermentation and storage cellar. In 2008, the growth of the brewery demanded the addition of six more unitanks. It was not possible to expand the existing automation system, which is based on the TI505 series of programmable logic controllers, and a new, modern automation system had to be selected and implemented. The selection criteria was that the new system had to reliably interact with the existing automation system, there could not be extended downtime, and the new automation system had to accommodate future expansions. In addition, the new system was supposed to allow for a distributed input/output system, which connects the various parts of an automation system in the brewery to the programmable logic controller via fieldbus, a communication link that reduces installation time by reducing the amount of wire that has to be connected back to the central controller, which is only one of the many advantages of this state-of-theart automation tool.

Peter Koestler graduated in 1998 with a Dipl.-Ing. degree in brewing and beverage technology from the Technical University of Munich in Weihenstephan, Germany. He currently works as Brewery engineer for The Gambrinus Company in San Antonio, TX. In his position, he is responsible for engineering projects at the Spoetzl Brewery in Shiner, TX, and also provides engineering support for the BridgePort Brewery in Portland, OR, and the Trumer Brauerei in Berkeley, $C A$. His main focus is on process improvement through automation projects. He is also responsible for risk management programs and process safety management pertaining to ammonia refrigeration at the breweries. Through his wife's family, he was introduced to the fine art of Texas barbeque and was allowed entrance into the family competitive cooking team. Beer and barbeque-a match made in heaven.

\section{O-10}

Germany's first solar power plant for breweries

Presenter: Klaus Wasmuht, Krones AG, Neutraubling, Germany

Coauthor(s): Thomas Islinger, Krones AG, Neutraubling, Germany

Today the environmental impact of burning fossil fuel is one of the major tasks of humanity. However, saving and preserving our natural resources is not only a question of keeping a healthy environment, it also has a significant influence on ecological long-term objectives. The steadily increasing price of crude oil makes it necessary to think of alternative ways of generating energy; these thoughts affect all industries and branches and, in particular, beverage and brewing technology. Krones AG in Regensburg, Germany, in cooperation with the Hofmuehl brewery in Eichstaett, Germany took part in this challenge. During the last five years Krones and the Hofmuehl brewery developed and installed an energy supply system for the Hofmuehl brewery based on a solar power plant. The traditional brewery that was established in 1492 installed on its roof a battery of solar panels with a gross size of $1,400 \mathrm{~m}^{2}$. The system storage volume of $111.3 \mathrm{~m}^{3}$ of water provides a whole range of brewery sub-systems with steam, hot water, and energy for cooling, e.g., bottle washers, CIP systems, and flash pasteurization units. It is calculated that the energy systems will save approx. 85,000 L of heating oil per year that equals around $60 \%$ of the yearly energy consumption of this 
brewery. According to the calculations of the Hofmuehl brewery managing director, the investment will be amortized within a period of about 10 years. This solar solution trumps other concepts of alternative energies like organic fuel, rape oil, and solar electricity with regard to costs, availability, and environmental care. It is especially beneficial that in periods of high energy consumption, i.e., summer, the solar system produces more energy than in periods of low beer consumption, i.e., winter. Furthermore the internal heat storage is able to overcome phases with smaller entries of solar energy. The environmentally conscious Hofmuehl brewery in Eichstaett, Germany, took the first steps in becoming partially powered by the sun, although it wasn't an easy way and there were many hurdles before the system was completely installed and successfully set up in 2008.

As a technological expert in the field of beverage technology, bottling processes, and brewing, Klaus Wasmuht holds more than 50 patents as an inventor. He is highly active in broadening the borders of machine building in beverage technology in his function as the head of the Department for Conceptual Engineering of Process Technologies at Krones Ag in Regensburg, Germany. Klaus'first contact with the brewing industry as a brewer apprentice took place when he was still in school in 1975. In 1984 he finished his studies of brewing technology at Technical University of Munich in Weihenstephan and graduated as brew and malting master. Up to 1989 Klaus worked as a commissioning technologist in the field of mechanical engineering in Reinhausen, Germany, when he joined Krones as a deputy department manager for technology. In 2003 he took over the position as head of the department. Today Klaus is highly active in this function, while he also has taken over additional responsibilities, like heading the Department for Conceptual Engineering of Process Technology at Krones headquarters in 2007.

\section{0-11}

Novel beer products with pharmacodynamic properties enriched with Ganoderma lucidum and thyme

Presenter: Sasa Despotovic, University of Belgrade, BelgradeZemun, Serbia

Coauthor(s): Ida Leskosek-Cukalovic, Miomir Niksic, and Vele Tesevic, University of Belgrade, Belgrade-Zemun, Serbia; Mihailo Ristic, Institute for Medicinal Plant Research, Dr. Josif Pančić, Belgrade, Serbia; Viktor Nedovic, University of Belgrade, Belgrade-Zemun, Serbia

Beers with mushrooms and medicinal herbs are interesting, not only because of their specific and unique pharmacodynamic properties, but because of their very specific and pleasant sensorial characteristics as well. Mushrooms like Ganoderma lucidum have been used for thousands of years in traditional folk Asian medicine. G. lucidum has gained wide popularity as a cultivated edible mushroom with high nutritious value and extremely promising medicinal properties. Its intracellular and extracellular polysaccharides have been proven to inhibit the growth of several cancer cells, and in addition, it also produces many oxygenated triterpenes, especially ganoderic acid, with various biological functions, such as cytotoxicity to hepatoma cells, inhibition of histamine release, inhibition of cholesterol synthesis and absorption, stimulation of platelet aggregation, and inhibition of thrombin-induced platelet aggregation. Thyme (Thymus vulgaris L.) is used in herbal and regular medicine and is most commonly recommended for the treatment of dry, spasmodic coughs. G. lucidum and thyme could be used as the basis for developing a wide variety of products with specific physiological activity. This study gives an overview of the potential of the herb $T$. vulgaris and mushroom $G$. lucidum as sources of active ingredients for functional drinks and beer-based phytopharmaceuticals. Thyme extract was prepared using the conditions prescribed for tincture according to Pharmacopoeia. Ganoderma extract was made by ethanol extraction, preformed with $50 \%(\mathrm{v} / \mathrm{v})$ and $70 \%(\mathrm{v} / \mathrm{v})$ solution. Based on qualitative and quantitative analysis of active ingredients using GC and HPLC methods, the physiological effect was estimated, and the recommended dosage determined. Tincture was added aseptically to commercially produce bottled pills beers, taking into account the recommended daily doses and sensory acceptability. The paper deals with sensorial evaluation of the final products, determination of the bioactive substance content, potential therapeutic actions, and recommended dosages. Consumer acceptance of the beer was evaluated by testing five main characteristics: aroma, taste intensity of bitterness, quality of bitterness, and general impression.

Sasa Despotovic is a doctoral student in the Department of Brewing, Institute for Food Technology, Faculty of Agriculture, University of Belgrade, Serbia. He graduated from the Department of Brewing. Since 2008, Sasa has been an assistant teacher on the course Beer and Malt Technology. He is a member of the Serbian Society for Food and Nutrition. Sasa is currently working on a project investigating the possibilities for making novel beer products based on their potential pharmacodynamic action. He is interested in microbiology, food safety, and development of methods for antioxidant activity of beer-based products.

\section{0-12}

Optimizing malting and mashing conditions of oat (Avena sativa $L$.) as a raw material for alternate fermented beverages with high $\beta$-glucan content

Presenter: Martin Zarnkow, TU München, Freising

Weihenstephan, Germany

Coauthor(s): Alicia Munoz Isa and Martina Gastl, TU

München, Freising, Weihenstephan, Germany

Oats (Avena sativa) are one of the most popular cereals for human consumption. In the Middle Ages oats were the brewing cereal par excellence. Over the centuries, other cereals were substituted for oats, and their brewing properties were nearly forgotten. Today, oats are popular once more because of their excellent health-related properties. For people who suffer from celiac disease, oats are also of interest. Based on their historical use in brewing and their health-related properties, pilot malting trials were carried out with different cultivars, followed by brewing trials with a selected cultivar. The results obtained showed that oat malt is an appropriate choice for brewing. Response surface methodology was used to investigate the influence of three malting parameters, vegetation time, degree of steeping, and temperature, on the quality of oat malt. Each predictor variable was tested at three levels. Vegetation times were 6, 7, and 8 days, degrees of steeping were 42,45 , and $48 \%$, and vegetation temperatures were 12,15 , and $18^{\circ} \mathrm{C}$. Kilning temperatures of $80^{\circ} \mathrm{C}$ were used. Further on, mashing trials with exogenous enzymes were applied for filterable mashes with high $\beta$-glucan content. This work shows clearly that on the one hand RSM is a proven 
method for testing the malting conditions of unknown cereals, and on the other hand, A. sativa is a crop with potential as a raw material for alternate fermented beverages with high $\beta$ glucan content.

Martin Zarnkow apprenticed as a brewer and maltster from 1989 to 1991 at a small brewery in Frankonia. He completed a Dipl.-Ing. degree with an option in brewing technology in 1996 at the Technical University of Munich at Weihenstephan. He then worked for a year as a brewmaster in a mid-sized brewery in Germany. Since 1997, Martin has been a scientific assistant and head of the Beer Laboratory at the Lehrstuhl fur Technologie der Brauerei I at the TU Munich Weihenstephan. Since September 2005, Martin has been working as a doctoral research fellow at University College Cork, Ireland, on "Malting and Brewing with Non-traditional Cereals."

\section{0-13}

A rose by any other name-The importance of beer flavor terms in modern brewery operations

Presenter: William Simpson, FlavorActiV Limited, Chinnor, UK

Coauthor(s): Boris Gadzov, Evelyne Canterranne, Javier Gomez-Lopez, Ronald Nixdorf, and Richard Boughton, FlavorActiV Limited, Chinnor, UK

This year marks the 30th anniversary of the introduction by the MBAA and others of an international system for the naming of beer flavor attributes. The system has stood the test of time and, in the last decade, gained prominence with the introduction of stabilized beer flavor standards to train tasters. Web-based competence assessment schemes have allowed us to measure the degree to which tasters use terms consistently and the extent to which one term is confused with another. It is important that each and every flavor term encourages and facilitates action being taken in the brewery. Steps taken in response to tasting results can help ensure that desirable flavor characters are maintained in a brand of beer at the right level and facilitate elimination of off-flavors and taints from the product. In this paper we will review the terms used by brewers to describe their beers, critically evaluate what differentiates a good flavor term from an inferior one, discuss why some flavors are more easily recognized than others, and offer suggestions for improving the terminology to further facilitate practical beer flavor management.

Bill Simpson joined Scottish brewer Tennent Caledonian Breweries in 1977 as a trainee microbiologist. Studying parttime he gained a first-class honors degree in microbiology and a lot of brewery experience before embarking on a nine-year program of research with the Brewing Research Foundation $(B R F)$ in England. During that time he published extensively in areas such as flavor chemistry, brewery microbiology, and yeast. He rose to the position of principal scientist and head of fermentation before leaving BRF in 1995 to start two companies-Cara Technology and FlavorActiV. In addition to his ongoing research in the areas of beer flavor chemistry, sensory science, and yeast, Bill consults for a number of international brewery groups, with particular emphasis on process problem solving. He won the Institute of Brewing \& Distilling's (IBD's) Cambridge Prize for Brewing Research for his work on hop bitter acids and beer spoilage bacteria in 1991 and has published more than 100 scientific papers, books, and patents on brewing technology. Bill is a Fellow of the IBD and a member of the editorial board of the Journal of the American Society of Brewing Chemists.

\section{O-14}

Drinkability-A two-edged sword

Presenter: Michael Lewis, UC Davis Extension, Davis, CA

Drinkability is the brewer's mantra and holy grail: a beer should not be satiating or filling, it should be more-ish, crisp not heavy, tasty but not fatiguing, and should leave the consumer satisfied but willing and able to have another. The reasons are simple: 1) the profit is somewhere in the last bottle of the six-pack; and 2) the sooner it is gone the sooner it must be replaced. And therein lies something of a dilemma for an industry that preaches moderation: drinkability is a trait that is intended to encourage consumption. For craft brewers, however, the issue is somewhat different, because they may parse the word drinkability in a different way from my definition. They may equate drinkability with preference or liking or distinction or even with inventiveness, rarity, and cutting-edge uniqueness. There is, therefore, a trend within the craft segment to move to the extremes, and while these are fascinating avenues of brewing arts and science to explore, there is some danger of leaving the consumer far behind. The astonishing success of lime-flavored light beers does nothing to convince me that the American consumer in general is starved of Russian imperial stouts, for example, and is clamoring for them, interesting though such beers are. The craft beer segment of the industry needs to think about drinkability in a different way if it is to be anything but a fringe element in the marketplace, and the old idea of flavor balance might provide a clue to the future.

Professor Emeritus Michael Lewis taught the program in brewing science at the University of California at Davis for more than 30 years before retiring in 1995, and many of his former students now hold distinguished positions in the American brewing industry, large and small. Michael has been recognized by the university with the Distinguished Teaching Award and by the industry with the MBAA Award of Merit and Life Membership. Michael remains active in the industry; he is academic director of brewing programs in the University of California Extension, where the Master Brewers Program, which prepares students for the Institute of Brewing and Distilling examinations, is the flagship offering.

\section{O-15}

The effect of beer $\mathrm{pH}$ on colloidal stability and stabilization Presenter: Karl Siebert, Cornell University, Geneva, NY Coauthor(s): Penelope Lynn, Cornell University, Geneva, NY

Protein-polyphenol interaction is the most common source of haze in beer. Prior work showed that $\mathrm{pH}$ has a profound effect on the amount of haze formed with the same amounts of hazeactive (HA) protein and HA polyphenol, with a maximum slightly above $\mathrm{pH} 4$. The particle size distribution patterns of model system mixtures with different levels of HA protein, HA polyphenol, alcohol, and $\mathrm{pH}$ were determined. Particles of only a few distinct sizes were seen under each condition, and the sizes and proportions of particles were different at different pHs. Changes in particle size impact sedimentation (cold maturation and centrifugation) and filtration operations. The effects of $\mathrm{pH}$ on adsorbent effectiveness were studied with unchillproofed beer that was adjusted in $\mathrm{pH}$ before adsorbent 
treatment. The percent removal of HA protein by silica and the percent removal of HA polyphenol by PVPP were lowest at $\mathrm{pHs}$ where haze formation is greatest. It appears that this is due to competition for the HA species between the adsorbents and haze particles. The results are discussed in view of previous observations by other brewing scientists and factors that affect beer $\mathrm{pH}$.

Karl Siebert received a Ph.D. degree in biochemistry from Penn State in 1970. He then spent 18 years at the Stroh Brewery Company in Detroit, MI, where he held positions from research associate to director of research. In 1990, Karl joined Cornell University as professor of biochemistry in the Department of Food Science and Technology. He served five years as department chair and now has a predominantly research commitment. Karl is active as a consultant in beverage technology and chemometrics. He twice received MBAA Presidential Awards for papers he presented, and he and his colleague, Penny Lynn, received the ASBC Eric Kneen Memorial Award (for the best paper published in the Journal of the American Society of Brewing Chemists in the prior year) three times. Karl received the ASBC Award of Distinction in 1999. He is a member of the editorial board of the Journal of the American Society of Brewing Chemists. Karl's research interests involve foam and haze in beverages, the application of chemometric methods in food science, and assessment of microbiological risk.

\section{O-16}

Shelf-life stability of German "Lower Rhine" beer specialties

Presenter: Roland Folz, VLB-Berlin, Berlin, Germany

In Germany a lot of different traditional beer styles exist, which increasingly become of interest internationally. All these beer types have their own significance: on the one hand, as traditional beer styles that enrich the worldwide range of special beers with their own and unique character; and on the other hand, these beers especially form part of the regional culture and history, so they are synonymous with cultural identification and belong to the regional way of life. The special beer styles of North Rhine-Westphalia (mainly Alt and $K \ddot{o} l s c h$ ) have a fixed place also in the modern brewing world. In this region, brewing can be traced back further than 300 B.C. Nowadays, they can only survive in the national and international markets due to high quality demands with reference to the use of raw materials and the brewing process. In addition to historical and cultural backgrounds, modern production process and quality aspects are presented. Through the quality monitoring of these beers over years, the VLB has noticed a certain shift in the fingerprint. Furthermore, a widely monitored issue in the quality of these beer specialties is shelflife stability. Shelf-life stability does not include only flavor stability, but also non-biological stability and the stability of flavor-active components, such as bittering impressions. Research results obtained from a combined project of the VLB-Berlin and Weyermann Speciality Malts are presented.

Roland Folz apprenticed as a brewer and maltster at the Beck's brewery in Bremen, Germany. After working another year for the Beck's brewery, he started his studies in Berlin and received a Dipl.-Ing. degree in brewing technology from the Technical University, Berlin. After graduation, Roland became head of the Technical Department/Production at the
Preussen Pils brewery in Pritzwalk, Germany, for two years. In October 2006, Roland returned to VLB-Berlin as a global consultant for brewing technology, working in the Engineering and Packaging Department as the specialist for the filling department and brewing topics. In regard to his consulting practice, he is involved in teaching and research projects and manages the internationalization of VLB. Since autumn 2008, Roland has been the head of the Brewing \& Beverage Technology and Application Department at VLB-Berlin. This department includes the education and teaching part of VLB, as well as research activities regarding technological topics, global consulting, analytics, and services.

\section{0-17}

Flavor stability of novel malt-based beverages

Presenter: Moritz Krahl, TU München, Germany

Coauthor(s): Felicitas Stürmer and Thomas Becker, TU

München, Germany

In recent years a number of new malt-based beverages has been launched. As beer consumption in Western countries is decreasing due to multiple reasons, such as stricter alcohol limits and growing consumer awareness of the negative effects of alcohol abuse on overall health, the production of new products has gained growing interest in the brewing industry. Consumers are looking for new products with natural ingredients and health beneficial attributes. Little attention, however, has been paid to the flavor stability of such new products. This paper shows a new tasting scheme and the analysis of stale flavor compounds in these beverages. With some modification of well-known analyses, it is possible to describe the changes occurring in the aroma and flavor of innovative malt-based drinks. Sensory evaluation of the beverages has to be adjusted to their different ingredients. These are, aside from malt, particularly fruit juices and flavors. The chromatographic analysis of stale flavor compounds can be carried out according to the methods used for beer. In this work, commercially available beverages and beverages produced in pilot-scale volumes were analyzed with regard to flavor and aroma stability. The pilot-scale trial was carried out with malt extract that was fermented with lactic acid bacteria and mixed with fruit adjuncts prior to carbonization and bottling. All samples were forced aged, tasted, and analyzed. Most of the stale flavor compounds known for beer can be found in these beverages and show significant correlation with the taster's perception. Some components known from beer, however, could not be used to describe changes in alternative malt-based beverages, as these substances occurred in the fruit juices used. This work shows that well-known analyses can be used for new products. Only minor adjustments are needed.

Moritz Krahl was born in 1980 in Schwetzingen, Germany. After attaining the German Abitur (A-level certificate) in 2000, he began studying brewing and beverage technology at the Technical University of Munich, Weihenstephan. In 2005 he graduated with a Dipl.-Ing. degree and has since then been working as a doctoral student at the Chair for Technology of Brewing I in Weihenstephan. 


\section{0-18}

Use of a high-speed camera and vibration analysis to resolve production line problems

Presenter: Ryuhei Kuroda, Asahi Breweries, Ltd., Moriya, Japan

The lack methods for precisely determining where canned products on a production line encounter adverse impacts has proven problematic to date. However, a new method employing a high-speed camera that is capable of long recording times combined with vibration analysis of plant equipment has proven effective for identifying these impacts. Using this method, we were able to clarify the mechanism that resulted in "mismatched cans" (cans with false seams) in line $\mathrm{C} 4$ at the Ibaraki brewery and to develop a solution. The highspeed camera was used to locate the point at which cans tilted and became deformed (elliptical shape) on the filler in-feed conveyor. To resolve this problem, we replaced the in-feed conveyor with a multiple hinge-type model that employed less slack. The video was then analyzed using movement analysis software, and other can behaviors were digitized. In the next stage, the vibrations of the filler machine were analyzed, and their settings were verified with vibration analysis software. Combined use of the high-speed camera and vibration analyses made it possible to suppress adverse can behaviors and verify optimum machine settings. The ability of this method to resolve a long-standing problem proved to be effective and is likely to be used for solving similar problems in the future.

Ryuhei Kuroda completed an engineering master's degree at the University of Electro-Communication in Tokyo, Japan. In 2003 Ryuhei joined the Packaging Department, Ibaraki Brewery, Asahi Breweries, Ltd. From 2007 to the present, Ryuhei has worked at the Production Technology Center, Asahi Breweries, Ltd.

\section{O-19}

Cost-effective optical damage detection for crates of beverages based on induced oscillation

Presenter: Rainer Benning, University Erlangen-Nuremberg, Erlangen, Germany

Coauthor(s): Judith Forstner, Joanna Procelewska, and Christian Luschmann, University Erlangen-Nuremberg, Erlangen, Germany; Sven Franke, Heinrich Vogelpohl, and Horst-Christian Langowski, Technische Universität München, Freising-Weihenstephan, Germany; Antonio Delgado, University Erlangen-Nuremberg, Erlangen, Germany

Reliable damage detection for crates of beverages is of high interest for the brewing industry. To avoid interruptions in the production process, legal claims due to product liability, or negative influences for the brand image, damaged crates have to be removed from the pool, while intact crates have to remain. Usual optical methods in this field are not able to detect hidden cracks or aging of the crates. Furthermore, it is impossible to look at the complete crate with reasonable financial expenditure. In a novel approach, a system was developed where the crate oscillates due to external excitation. At first a laser vibrometer was used for detection of the response. It could be shown that oscillation was typical for the crates state and constituted a useful feature to discriminate between intact and damaged crates. However, to reduce the costs of the system, especially for small- and medium-sized enterprises, the vibrometer was replaced by a CCD camera, similar to the type that is presently used for logogram recognition. Although the resolution of the camera was lower in comparison to the vibrometer, there was an advantage, since the oscillation of an area could be taken into account instead of a single point. Through numerical simulation and experiments, a representative section of the crate was selected to find a structure, which enabled comparatively comfortable automatic detection of edges. Image processing algorithms evaluated the movement of the defined edges in horizontal and vertical directions. Because one of the boundary conditions is given by the number of crates that have to be tested in an industrial environment, the complete procedure had to be carried out within a second. Regarding the necessary fixation of the crate during excitation, decoupling from the transport belt to guarantee reproducible results, and, especially, duration of induced oscillation, nine images could be recorded for each crate. The difference between the position of the edges between two consecutive pictures was calculated, resulting in seven datasets that represented the displacement of the selected area with respect to time. The calculated values were used to set up an artificial neural network, which was trained to classify the investigated crate. A classification rate of above $99 \%$ would be the goal to limit the costs of unnecessarily sorting out intact crates. The complete system has presently been transferred to a pilot-scale solution that will be integrated into an industrial filling process for testing and comparison with the presently applied detection system.

Rainer Benning has a diploma degree from Technische Universität München in Technology and Biotechnology of Food. His doctoral work was on the simulation and optimization of the heat transfer process in the production of UHT milk by applying fuzzy logic. In 2003 he received his Ph.D. degree in the field of process automation from Technische Universität München. In 2006 he was transferred to the Institute of Fluid Mechanics, University ErlangenNuremberg. There he established the research group Process Automation of Flows in Bio- and Medical Technology. The development of hybrids, i.e., the combination of cognitive and classical mathematical methods, in optimization and automation of processes within food, beverage, and biotechnology is one of his key research interests. These hybrids are applied in various research projects for state detection and improving the control of complex processes, such as drying of pasta and wastewater treatment.

\section{O-20}

Creating a "greener" tunnel pasteurizer-A guide to assessing and reducing your tunnel pasteurizer's utility consumption

Presenter: Dave Duff, Barry-Wehmiller Company

The predominant method of beer pasteurization in North America today is tunnel pasteurization. Unfortunately, many of these pasteurizers are operating at less than optimal levels of utility usage. Couple that with limited utility-saving technologies and modifications to original designs to help increase throughput at the sake of utility efficiency, and the pasteurizer quickly becomes one of the best areas of opportunity for brewers with a focus on going "green." Unfortunately, the tunnel pasteurizer quite often becomes that large box in the center of the packaging floor that works tirelessly day in and day out, using a combination of steam and 
water to meet the quality requirements for beer pasteurization. However, few brewers actually have the tools to monitor the energy demands of the pasteurizer, and even when good maintenance practices are in place, many brewers lack the knowledge base within their organization required to troubleshoot changes to the pasteurizer's operation that lead to higher utility consumption. This paper examines the engineering fundamentals required for optimizing tunnel pasteurizer energy consumption, as well as the methods developed for auditing pasteurizer performance against its design standard. Included is a review of several opportunities for reducing energy demands, ranging from simple mechanical items to a number of cost-effective upgrades that will not only improve energy consumption but help create processes to maintain those new standards.

David Duff has been a member of the MBAA since 1982 and has held positions in his MBAA District, as well as contributed on the MBAA Technical Committee as a session moderator and speaker. David began his career with Labatt Brewing Company and held various packaging management roles in five different Labatt facilities throughout Canada. In 1997 David left Labatt to join forces with the Stroh Brewing Company and worked at their headquarters in Detroit, MI, as director of packaging operations until the brewery ceased operations. He is now with Barry-Wehmiller Company as sales executive for the North American brewing industry.

\section{0-21}

\section{The Draught Beer Quality Manual}

Presenter: Ken Grossman, Sierra Nevada Brewing Co. Coauthor(s): Paul Gatza, Brewers Association; Charles Kyle, Sierra Nevada Brewing Co.; Neil Witte, Boulevard Brewing Co.; Scott Nielsen, MillerCoors

The Draught Beer Quality Guidelines group was formed in March 2007 under the direction of the Brewers Association Technology Committee. The working group is composed of employees at Anheuser-Busch InBev, Bell's, Boulevard, the Brewers Association, the Cicerone Certification Program, Gambrinus, Lucky Bucket, MillerCoors, New Belgium, Sierra Nevada, and Upstream. The overriding mission on the group is to improve the quality of draught beer dispensed to our customers. Distributors, wholesalers, retailers, or draught installation teams may install a draught system. But once in place, each system commonly pours a wide range of brewers' and suppliers' products. We have sought to bring the industry together to agree on guidelines that present everyone's beer in optimal condition. When handled properly from brewery to bar, draught beer delivers what many consider to be the freshest, most flavorful beer available to the consumer. But, the job does not end once the keg is tapped and the beer begins to flow. Good beer quality depends on proper alignment of the dispense variables and consistent housekeeping practices. The draught quality working group focused on the areas of draught system components, temporary draught dispense, equipment, and configurations for direct-draw draught systems, equipment and configurations for long-draw draught systems, system balancing, storage, glassware cleaning, pouring, and system maintenance and cleaning.

Ken Grossman is founder, owner, president, and master brewer of Sierra Nevada Brewing Co. In 1980, after three years of design, fabrication, construction, and experimental brewing,
Sierra Nevada opened in a small warehouse in Chico, CA. By 1987, demand exceeded capacity, and Ken designed a new brewery featuring $a$ pub and a restaurant. A decade later the brewery expanded once again and presently brews and ships more than 650,000 barrels of beer per year. Ken continues to be personally involved in a hands-on manner with all aspects of the brewing process, plant development, and equipment maintenance. Sierra Nevada Brewing Co. has a proud history of good corporate citizenship by operating in an efficient and environmentally sound manner. Ken considers resourcefulness a philosophy and has pioneered efforts to integrate environmental values into management decisions and practices. The Chico-based brewery employs more than 400 people and distributes its products throughout the United States, Great Britain, and select European markets.

\section{O-22}

The management of brewery fermentation: Theory versus practice, a critical comparison

Presenter: Chris Boulton, University of Nottingham

The fermentation stage of brewing exerts a critical outcome on process efficiency, process consistency, and beer flavor and aroma. Many of the studies that have sought to elucidate the relationships between yeast metabolism, the conditions established at the start and during fermentation, and the outcome of the process have been performed at either laboratory or pilot scale. At production scale, the true relationships between fermentation control parameters and fermentation performance are often less straight forward owing to the practicalities of real-world brewing. In consequence, the choice of appropriate values for the major control variables and the sequence of events that culminate in the initiation of fermentation are commonly derived from empirical experimentation and observation. In previous communications, this author has demonstrated that a lack of appreciation of the impact of the conditions to which yeast is exposed in commercial brewing can result in inconsistencies in fermentation performance. In addition, levels of yeast stress may be increased to the extent that viability can be compromised, with the predictable concomitant negative effects on beer quality. In this presentation examples are provided that illustrate how an appreciation of the ways in which theoretical studies of fermentation theory, in particular the response of the yeast genome to the conditions of realworld brewing, can be exploited to ensure that fermentation proceeds in a consistent and predictable manner.

Chris Boulton is a microbial physiologist by training and has had nearly 40 years of experience in research into yeast biochemistry. He has written and presented numerous papers and is the co-author of two current standard brewing textbooks. He is a Fellow of the Institute of Brewing and Distilling and a member of the American Society of Brewing Chemists. His career in brewing began in 1984 in the Research Department of Bass Brewers in Burton on Trent, UK, and spanned more than 23 years. During this time he specialized in fermentation studies, in particular the impact on yeast of the use of very large capacity vessels. After stints during which Bass was subsumed into InBev and then Coors Brewers, Chris joined the Department of Brewing Science at the University of Nottingham, UK, where he is currently a special professor and teaching fellow. 


\section{O-23}

Standardizing residence time in the fermenterUnderstanding the causes of lag-phase variability Presenter: Katherine Smart, University of Nottingham Coauthor(s): Katherine Miller and Christopher Boulton, University of Nottingham

To achieve sustainable brewing fermentations requires improvements with regard to consistency of fermentation duration and an overall reduction in residence time.

Considerable variability in fermentation rate occurs during the first few hours when yeast progresses through the lag phase. This alone can significantly modify total fermenter residence time, particularly for fermentations that use freshly propagated yeast and younger generation yeast. Lag phase may be defined as the time required to progress from pitching to initial bud emergence, and the factors controlling this progression during brewing fermentations are poorly understood. Variability of lag-phase duration has been attributed to several factors, including the generation number of the yeast, batch-to-batch differences in wort composition, fermenter physical environment, and rate of yeast dispersal within the fermenter. In this presentation, lag-phase progression during fermentation has been assessed by quantifying DNA synthesis using flow cytometry and fermentation key performance indicators. It is proposed that lag phase can be standardized by careful management of propagation and fermentation.

Katherine Smart completed a B.S. degree (with honors) in biological sciences at Nottingham University in 1987 and was awarded the Rainbow Research Scholarship to complete a Ph.D. degree in brewing yeast and fermentation at Bass Brewers, Burton-on-Trent. She then moved to Cambridge University to take up an appointment as research fellow in the Department of Plant Sciences. In 1992, she joined Oxford Brookes University as a lecturer. In 2000, she was appointed to Scottish Courage Reader in Brewing Science and was subsequently appointed to Fellow of the IBD. In 2005 Katherine moved to the University of Nottingham, where she became the SABMiller Professor in Brewing Science. In 2009 she became a Fellow of the Royal Society of the Arts, Manufacturing and Commerce. Katherine has received several awards for her research, including the IBD Cambridge Prize (1999), Royal Society Industrial Fellowship (2001-2003), and Save British Science Award at the Houses of Parliament in the United Kingdom (2003). Katherine has previously held the roles of chair of the IBD International Section and ASBC international director. Her research interests include industrial yeast cell biology, brewing yeast handling and stress responses, fermentation efficiency and consistency, yeast flocculation, and bioethanol fermentations. She has published extensively.

\section{0-24}

Use of a miniaturized fermentation assay to assess the fermentation characteristics of six yeast strains Presenter: Alex Speers, Dalhousie University Coauthor(s): Anna Jean Reid, Dalhousie University; Lyn Kruger, Siebel Institute of Technology

Yeast strain selection is a time-intensive and resourceexpensive process. Strain selection depends on various factors, including flavor production, flocculation behavior, attenuation limit, and fermentation speed. However, it is impractical to test hundreds of potential yeast strains for these characteristics at production scale. The aim of this research is to test if the physical differences in fermentation characteristics affected by yeast strain can be identified and compared using a miniaturized fermentation assay. Industrial wort was fermented with six different yeast strains (A, SMA, and Labatt Culture Collection [LCC] 125, 1208, 1209, and 1240) in small-scale test-tube fermentation vessels. The yeast were either ale (LCC 125, 1209, and 1240) or lager (A and SMA) and varied in their genotypes and flocculation phenotypes (NewFlo or Flo1). Each fermentation was conducted at $21^{\circ} \mathrm{C}$ with wort supplemented with $4 \%(\mathrm{w} / \mathrm{v})$ glucose and completed in $72 \mathrm{~h}$ (Lake et al., J. Am. Soc. Brew. Chem., 2008). Turbidity and density measurements were collected throughout the fermentations, and non-linear modeling was used to compare each yeast strain's fermentation parameters. This method showed differences between strain attenuation of the wort, as well as some differences in maximum fermentation rates. The results provide evidence that small-scale fermentations can be used to compare the fermentability of different yeast strains, as well as their maximum rate of fermentation and the time at which this occurs. This method could be useful in preliminary screening of new yeast strains in large-scale production.

Alex Speers is a professor in the Food Science and Technology program at Dalhousie University, Halifax, NS, Canada. Alex received his graduate education in food science at the University of British Columbia, Vancouver, BC, Canada. At Dalhousie University, he instructs students in brewing science, quality assurance, and food product development. In the past, Alex has been employed in the Quality Assurance Departments of both Labatt and Molson Breweries. His current research interests include various aspects of the brewing process, including fermentability, yeast flocculation, premature yeast flocculation, extract calculations, and the properties of (and problems created by) $\beta$-glucan and arabinoxylan polymers. He has organized and/or presented brewing workshops in China (Changzhou, Qingdao, and Yangzhou; 1997-2005) and recently at brewing conferences in Honolulu, HI; Nashville, $T N$; San Francisco, CA; and the International Brewers Symposium: Yeast Flocculation, Vitality, \& Viability in Boston, MA, in 2009. Alex has spent sabbaticals at CUB/Fosters in Melbourne, Australia, and the Columbia Brewing Company in Creston, BC. On occasion he instructs at the Siebel Institute of Technology. Alex belongs to several professional societies and is a member of the editorial boards of Food Research International, the Journal of the American Society of Brewing Chemists, and the Journal of the Institute of Brewing. He also currently chairs the Editorial Board of the Master Brewers Association of the Americas. He has published or presented more than 100 papers.

\section{O-25}

Cell wall modification: State of play

Presenter: Charles Bamforth, University of California, Davis, CA

We have come a long way from the pioneering work of the likes of Luchsinger and Preece in understanding the composition and degradation of the cell walls of the starchy endosperm of barley. Whereas the ins and outs of the heatsensitive endo-barley- $\beta$-glucanases are well-understood, we now appreciate the intimate role that enzymes such as carboxypeptidase, feruloyl esterase, acetylxylan esterase, 
arabaninofuranosidase, and endo-xylanases play in determining the breakdown of glucan in malting and mashing. This complex enzymology is reviewed in such a way as to highlight the practical realities of achieving homogeneous modification and the fewest brewhouse problems.

Charlie Bamforth is the Anheuser-Busch Endowed Professor of Malting \& Brewing Sciences at the University of California, Davis. He has been part of the brewing industry for 31 years. He is the former deputy director-general of Brewing Research International and research manager and quality assurance manager of Bass Brewers. He is a special professor in the School of Biosciences at the University of Nottingham, England, and was previously visiting professor of brewing at Heriot-Watt University in Scotland. Charlie is a Fellow of the Institute of Brewing \& Distilling, the Institute of Biology, and the International Academy of Food Science and Technology. Charlie is editor-in-chief of the Journal of the American Society of Brewing Chemists and a member of the editorial boards of several other journals, including the MBAA Technical Quarterly. Charlie has published innumerable papers, articles, and books on beer and brewing, most recently editing Beer: A Quality Perspective (Academic Press). For 15 years in his native England, he wrote about soccer and has been published extensively in match-day programs and magazines. He also authored a book about goalkeepers. Charlie has been married to Diane for 32 years and they have three children and one grandchild.

\section{0-26}

Bioactive compounds in the malting process

Presenter: Moritz Krahl, TU München

Coauthor(s): Thomas Becker, TU München

Nowadays human nutrition is mainly based on only three cereals, wheat, rice and corn, which contribute over $75 \%$ to the world's starch production. At the same time, diseases caused by wrong or unbalanced diets are causing severe problems in Western countries. In this regard, the enrichment of the malting process with bioactive compounds, with the objective of providing beneficial health effects to the consumer, is a very important field. The malting process is influenced by the quality of the raw material and several process parameters (e.g., moisture, temperature, and time), and the enrichment of bioactive compounds depends on the same variables. A statistical design of experiments (DOE) approach (response surface methodology) was used to evaluate the interactions of the influential factors and optimize the enrichment process. One group of the functional components we investigated is the arabinoxylans. In order to investigate this group of substances, it was necessary to establish a method for determining watersoluble and water-insoluble arabinoxylans. The method we used consists of acidic hydrolysis of the arabinoxylans, followed by HPAEC/PAD detection. Using this method, we were able to enrich water-soluble arabinoxylans in wheat malt. Another interesting group of components is the flavonols. We established a method for the characterization of flavonols like rutin, vitexin, and quercetin by HPLC separation. This method has helped us to determine optimum malting parameters for the enrichment of these functional components in buckwheat malt. Additionally, changes in the vitamin $\mathrm{B}_{1}$ and $\mathrm{B}_{2}$ content of cereals were monitored during the whole germination and malting process of different cereals, as well as the changes in water-soluble arabinoxylan and fructan.
Moritz Krahl was born in 1980 in Schwetzingen, Germany. After attaining the German Abitur (A-level certificate) in 2000, he began studying brewing and beverage technology at the Technical University of Munich, Weihenstephan. In 2005 he graduated with a Dipl.-Ing. degree and has since then been working as a doctoral student at the Chair for Technology of Brewing I in Weihenstephan.

\section{O-27}

Should winter barley breeding be intensified? Presenter: John Bryce, Blacksburg Brewing Co. Coauthor(s): Felipe Galastro Perez, AB InBev

Two-row spring barley has historically been favored over tworow winter barley for malt production in most countries. Recent poor malting barley yields worldwide, increased global beer consumption, and increased competition for acreage (as demand for bio-fuel crops and feed barley rises) all threaten the availability and affordability of traditional two-row spring malting barley. Furthermore, recent climate conditions have caused an increase in protein levels of typically low-protein spring barley varieties, which is a key differentiation from winter barley. New winter barley varieties have shown improvements in cytolytic modification and have been optimized further for lower viscosities, higher friability, lower protein content, and higher extract - the main reasons behind winter barley's historical lack of acceptance. A shift to winter malting barley is likely to result in a more stable supply for the industry and a better return for growers. As the line between spring and winter barley quality is blurred and the availability and price of two-row spring barley is threatened, the use of two-row winter barley for malting is of increasing interest. In this study, a pilsner malt was produced from a new winter barley variety in the VLB micromaltery. Subsequent malt analyses indicated the finished malt was of high quality and showed many parameters in ranges typically associated with quality malt produced from spring barley. Pilot brewery trials confirmed these results, suggesting the need for additional research directed toward the optimization of winter barley varieties for malt production.

John Bryce has been an MBAA District Mid-Atlantic member since 2006. As a Virginia Tech alumnus, John founded Blacksburg Brewing Co. in 2002 and has also worked in several other Virginia craft breweries, including Capital City Brewing Co., Old Dominion Brewing Co., and Starr Hill Brewing Co. In 2008, John graduated from Versuchs- und Lehranstalt fur Brauerei in Berlin with the title brewmaster, $V L B$. John is currently brewmaster with Roanoke Railhouse Brewery, as well as owner of Blacksburg Brewing Co.

\section{O-28}

Addressing North American malting barley production restraints

Presenter: Michael Davis, American Malting Barley

Association, Milwaukee, WI

Coauthor(s): Scott Heisel, American Malting Barley

Association, Milwaukee, WI

Barley acreage has declined to historic lows in the U.S. in the last 20 years, with a more recent and smaller decrease in acres in Canada. The American Malting Barley Association, Inc. (AMBA) is addressing the U.S. decline through enhancement of the national barley research infrastructure to address major 
production restraints, including winter hardiness, drought tolerance, and diseases, coupled with superior malting and brewing quality. AMBA is also working to improve the competitiveness of barley through advocacy for equitable federal farm programs, including viable crop insurance, and through education and promotion activities. Malting barley development is a public/private partnership, with most of the variety development and supporting research conducted at public universities and USDA facilities. Research on varieties and practices to increase production under drought conditions and new high-yielding cold-tolerant winter varieties will increase malting barley production. Federal policies play a significant role in whether farmers plant barley. AMBA addresses this through its advocacy for equitable federal farm programs and crop insurance products. AMBA worked closely with the National Barley Growers Association for a 2008 Farm Bill that reduces inequities by raising barley loan rates and target prices. Also included in the bill are changes to federal crop insurance for barley, making it easier to develop new products and providing coverage for quality losses under the Malting Barley Quality Endorsement. AMBA and NBGA continue to advocate for additional enhancements to crop insurance. Education and promotion of malting barley production is conducted in collaboration with the Institute for Barley and Malt Sciences. AMBA also collaborates with the Brewing and Malting Barley Research Institute, its Canadian counterpart.

Mike Davis is president of the American Malting Barley Association, Inc. (AMBA), a nonprofit trade association composed of major U.S. brewing and malting companies. AMBA's mission is to encourage and support an adequate supply of high-quality malting barley for the malting and brewing industry and increase our understanding of malting barley. Mike received a B.S. degree in biology from the University of Connecticut, an M.S. degree in agronomy from Purdue University, and a Ph.D. degree in agronomy, with a minor in biochemistry, at the University of Nebraska. Following the completion of his Ph.D. degree, he was employed as a research associate and lecturer in the Department of Agronomy and Department of Soils, respectively, at the University of Wisconsin. In 1983 he began his career with AMBA as vice president and technical director. In 1986 Mike was promoted to executive vice president and in December 1990 he was elected president. Mike is chair of the AMBA Technical Committee; executive secretary of the National Barley Improvement Committee and U.S. Barley Genome Project; member of the, U.S. Wheat \& Barley Scab Initiative Executive and Steering Committees; member of the Barley Coordinated Agricultural Project Executive and Scientific Advisory Committees; and co-chair of ARS Fargo Research Partners.

\section{0-29}

The influence of hop products on lager beer staling Presenter: Patricia Aron, Oregon State University, Corvallis, OR

Coauthor(s): Thomas Shellhammer, Oregon State University, Corvallis, OR

Hop acids and polyphenols have antioxidant properties that show potential to markedly improve the antioxidant capacity of unhopped lager. This study examined the influence of separate kettle treatments on the staling behavior of lager beer: spent hop material (from $\mathrm{CO}_{2}$ extraction), $\alpha$-acid extract, iso- $\alpha$-acid extract, and hop pellets. Using accelerated storage conditions, where beer was kept at $30^{\circ} \mathrm{C}$ for 8 weeks, antistaling effects and antioxidant properties of the hop treatments were assessed chemically by FRAP, EPR, and \% Trans versus Cis iso- $\alpha$-acids by HPLC, while qualitative staling effects were assessed by a trained human panel via a descriptive analysis sensory protocol. Results indicate that hopping treatment significantly affected the initial \% Trans, with the spent hop treatment having the highest \% Trans at week $0(P<$ $0.05)$. Spent hop treatment produced a beer that was most susceptible to loss of trans-iso- $\alpha$-acids during storage, even when stored at $0^{\circ} \mathrm{C}(P<0.05)$. Analysis of the beer samples by FRAP indicated that using pellets and spent hop material improved the antioxidant capacity of fresh finished lager beer. Moreover, after 8 weeks of storage, regardless of temperature, lager beers produced with pellet $(P<<0.001)$ and spent hop $(P<<0.001)$ treatments maintained significantly higher antioxidant capacity as measured by FRAP relative to the control beer, whereas the $\alpha$-acids extract and iso-dosed treatments were not significantly different than the unhopped control. In contrast, EPR data yielded results contradictory to the FRAP data. Sensory analysis of the $30^{\circ} \mathrm{C}$ storage treatment indicated that unhopped controls were highest in cardboard aroma, while the pellet treatment presented the lowest. The format of the hop material used during brewing can influence flavor stability in terms of antioxidant power and development of oxidized/age-related flavors during storage.

Patricia Aron is a doctoral candidate in food science and technology at Oregon State University. She currently studies the effects of hop polyphenols on lager beer flavor stability under the guidance of Tom Shellhammer. She obtained a B.S. degree in biochemistry from Elmira College in Elmira, NY, in 2000 and in 2007 obtained an M.S. degree in food science and technology from Oregon State University, investigating the extraction of phenolics during red wine fermentation.

\section{O-30 \\ Maximizing hop aroma and flavor through process variables}

Presenter: Van Havig, Rock Bottom Breweries, Portland, OR

Craft brewers face the challenge of creating beers with high levels of bitterness, hop flavor, and aroma from an extremely limited supply of aroma variety hops. This paper presents the findings of an experiment conducted by 35 breweries in the Rock Bottom Breweries group in which beers with identical recipes (the same gross malt and hop bill) were brewed, with the only variation in process being the time and manner of the finishing hop additions. Breweries were assigned one of four final hop procedures: 1) $1 \mathrm{lb} / \mathrm{bbl}$ of hops for $50 \mathrm{~min}$ of postboil kettle residence; 2) $1 \mathrm{lb} / \mathrm{bbl}$ of hops for $80 \mathrm{~min}$ of postboil kettle residence; 3) $0.5 \mathrm{lb} / \mathrm{bbl}$ of hops for $80 \mathrm{~min}$ of postboil kettle residence and $0.5 \mathrm{lb} / \mathrm{bbl}$ of hops as dry hops; or 4) $1 \mathrm{lb} / \mathrm{bbl}$ of hops as a dry hop only, with no final kettle addition. In addition, the sulfate levels in the brewing water of each beer were noted. The beers were then assessed by a sensory evaluation panel. We were able to show that process variables in terms of time and manner of hop addition have statistically significant effects on the perception of bitterness, hop aroma, hop flavor, citrus character, fruit character, grassy character, and malt perception. We also found a statistically significant negative correlation between the intensity of hop flavor and the level of sulfate in the brewing water. 
Van Havig has been a member of MBAA since 2002. He started brewing in 1995 at the Minnesota Brewing Company in St. Paul, MN, before moving to the Rock Bottom Brewery in Minneapolis, MN. Since then he's been the brewmaster of the Bethesda, MD, and Portland, OR, Rock Bottoms. He has been a regional brewer with Rock Bottom since 1998 and has been in charge of the company QA/QC program since 2004. He's been a board member of the Oregon Brewers Guild since 2005 and was the guild president in 2007 and 2008. Van was educated at Reed College, the London School of Economics, the University of Minnesota, and the Siebel Institute of Technology.

\section{0-31}

Influence of wort boiling parameters on the degradation of iso- $\alpha$-acids

Presenter: Sebastian Kappler, TU München

Coauthor(s): Moritz Krahl and Thomas Becker, TU München

Iso- $\alpha$-acids are the major contributor to the bitter perception in beer. They contribute to over $85 \%$ of the overall bitterness of traditional beers. In the brewing process, however, only about $30 \%$ of the $\alpha$-acids present in hops are isomerized and transferred into the finished beer. One of the reasons for the occurring losses in the brewing process is the poor solubility of unisomerized $\alpha$-acids in wort due to the wort $\mathrm{pH}$ during boiling. This problem could be solved by a higher $\mathrm{pH}$ or dosage of adjuncts that improve their solubility, using both of course is not practicable. On the one hand losses occur due to $\alpha$-acids that are not isomerized and on the other hand due to iso- $\alpha$-acids that are degraded during the wort boiling process. This problem is even more pronounced if pre-isomerized kettle extract is used. Degradation products of iso- $\alpha$-acids contribute as well to the perception of bitterness, but to a much smaller extent. These degradation products are not well understood. Previous work showed that about $20 \%$ of the dosed $\alpha$-acids are found in the trub or in isomerized or unisomerized form in the cooled wort. In this work the influence of the wort boiling parameters on losses of iso- $\alpha$-acids are shown. Additionally, a new liquid chromatographic method for the detection of degradation products is presented, and these degradation products are characterized. The results presented in this paper provide a better understanding of the conversions that take place during the brewing process. Suitable approaches for an improved yield are shown!

Sebastian Kappler was born in 1979 in Hohenwart in Bavaria, Germany. He passed his Abitur (A-level certificate) in 1999 and worked as a brewer in the Augustiner brewery in Munich, Germany, from 2000 to 2003. From 2003 he studied brewing and beverage technology at TU Munich and graduated with a Dip.-Ing. degree in 2008. Since then he has worked as a postgraduate researcher at the Chair for Brewing and Beverage Technology in Weihenstephan, Germany.

\section{0-32}

Influence of filtration and stabilization on beer quality parameters and utilization rate of hop downstream products

Presenter: Andreas Gahr, Hopfenveredlung St. Johann GmbH \& Co. KG, Germany

Coauthor(s): Christina Schönberger, Joh. Barth \& Sohn GmbH \& Co. KG, Germany; Gero Spika, BASF SE, Germany
Hop downstream products as tetra- and iso- $\alpha$-acids are used to adjust bitterness and foam properties in beers. Normally these products are added during filtration. Not only do certain product properties such as $\mathrm{pH}$ value and hydrophobic character influence their solubility and utilization rates, filtration and stabilization do as well. Filtration and stabilization are crucial parts of the beer process, as quality parameters such as clarity, flavor, and flavor stability are directly influenced in the filter cellar. Utilization rates of downstream products added during filtration are said to be within 60-90\%. However, it is not clearly understood what kind of physical reactions take place that influence the utilization rate as well as the physical and sensory properties of the beers. In this project, different filtration and stabilization combinations and their effects on tetrahydro-iso- $\alpha$-acids and iso- $\alpha$-acid utilization were investigated. Four different filtration and stabilization combinations, consisting of diatomic earth, silica gel, PVPcrosslinked, and a kieselguhr-free processing aid (based on polystyrene and PVPP), were used to investigate the utilization of tetrahydro-iso- $\alpha$-acids and iso- $\alpha$-acids.

Andreas Gahr was trained for two years on the job as a brewer and maltster at the Augustiner Brewery, Munich, Germany. He received a brewmaster degree from the Technical University Munich-Weihenstephan in 1994 and worked for another four years at the university for the Chair of Brewing Technology I. Since 1998 Andreas has been the head of the Research Brewery St. Johann, which belongs to the hop processing company of Hopfenveredlung St. Johann GmbH \& Co. KG and deals with all kinds of hop-related brewing trials and product development, as well as technological and raw material trials for suppliers and the whole brewing industry.

\section{O-33}

\section{Energy-saving concept in a German brewery with a} production capacity of $250,000 \mathrm{hL} / \mathrm{annum}$

Presenter: Gerrit Bluemelhuber, Doemens e.V., Graefelfing, Germany

Energy costs have increased continuously during the past years. For breweries, especially, this is a big cost factor, because the demand for energy in breweries is very high. In a German brewery, a concept was worked out to lower the cost of energy. First, the brewery's actual energy consumption was evaluated. The main energy users were monitored by a measurement technique for a few weeks. With the results in hand, a concept was worked out with a detailed calculation of saving potentials versus costs for the necessary investments in machinery to realize the potential savings. Improvements were made in the brewhouse, the steam boiler, refrigeration plant, and compressed air system. The savings in the brewhouse were realized by installing an evaporation condenser and a wort booster in combination with a heat accumulator. The steam boiler was upgraded with an economizer; the heat of the flue gas is now used to pre-heat the boiler feedwater. At the same time, the pressure in the steam boiler was reduced from 8 to 6 bars, which was another cost savings. In the refrigeration plant, a new compressor with an intercoller was installed. Also the evaporating temperature was changed from -10 to $-5^{\circ} \mathrm{C}$. The storage cellar was supplied with a ventilating system, which allowed the storage cellar to be cool downed with surrounding air in winter. The compressed air system was first checked for leaks. After remove every leak, the system 
pressure was lowered from 8 to 6 bars, which could be realized by installing a larger pressurized tank. Before we started to institute the energy saving concept, the brewery had energy costs of about $\$ 610,000 /$ year. After instituting the mentioned measures, the costs were about $\$ 465,000 /$ year. The ROI for the necessary investments was at about 24 months.

Gerrit Bluemelhuber was born in Mainz, Germany. After working ins the Sonnenbrauerei, Mainz, Germany, he started his studies in Weihenstephan, where he received a Dipl.-Ing. degree in brewing and beverage technology in 1996. After that he worked at the Technical University of Munich, where he received his Ph.D. degree in 2002. From 2004 to 2009 he worked in his own engineering firm as a consultant for energy and environmental techniques. Since April 2009 Gerrit has been the managing director for consultancy at Doemens in Graefelfing, Germany. He is responsible for the complete consultancy portfolio of Doemens and for the scientific projects that are executed by Doemens.

\section{O-34}

Renewable energy from brewery wastewater-A case study

Presenter: Michael O’Neil, Applied Technologies, Inc., Brookfield, WI

Coauthor(s): Dennis Totzke, Applied Technologies, Inc., Brookfield, WI; Corey Zarecki, Gundersen Lutheran Administrative Services, La Crosse, WI

City Brewing Company (formerly G. Heilman Brewing Company), located in La Crosse, WI, is a contract brewery and brews beer and a variety of specialty beverage drinks under many company private labels. City Brewing uses anaerobic treatment to pre-treat its brewery wastewater prior to discharge to the local publically owned treatment works. Biogas composed of approx. $60 \%$ methane is generated during anaerobic treatment. The biogas was formerly burned in a flare (waste gas burner), so it could be safely discharged to the atmosphere. Gundersen Lutheran Hospital, with a goal of offsetting all of its hospital energy consumption with "green" energy, partnered with City Brewing to construct a state-ofthe-art biogas conditioning and cogeneration system that is used to remove impurities in the biogas and then burn the biogas in an internal combustion engine to create electrical power and heat. The cogeneration system will produce up to $633 \mathrm{~kW}$ of electrical power and up to $345 \mathrm{~kW}$ of heat in the form of exhaust hot water. High levels of hydrogen sulfide (as high as 25,000 ppmv) in the biogas required an extensive biogas cleaning and conditioning system to be installed upstream of the cogeneration engine. This case study will present an in-depth look at some of the challenges that were overcome in the design and construction of this system and will provide valuable information to any brewery considering the addition of a renewable energy recovery system to its facilities.

Mike O'Neil is a senior environmental process engineer specializing in anaerobic and renewable energy systems. He has worked in the environmental engineering field for more than 12 years, 10 of which he has spent with Applied Technologies. Mike has B.S. and M.S. degrees in engineering from the University of Illinois-Champaign and conducted feasibility studies for anaerobic systems while at the university. He has significant experience in the design and construction of anaerobic and aerobic wastewater treatment plant systems in the beverage industry. Mike has spoken several times at the annual Anaerobic Treatment of High Strength Industrial Wastes conference sponsored by Marquette University and has been a presenter at the Iowa State University Technical conference, at the MBAA Convention in Nashville, TN, in 2007, and at the MBAA Midwest Technical Conference in Madison, WI, in 2008.

\section{O-35}

Environmental activities for realization of a sustainable eco-brewery-Resonating with people and nature Presenter: Yuki Osako, Suntory Ltd., Kyoto, Japan Coauthor(s): Kuremi Nishimoto, Minoru Yoshida, Eiji Mizuuchi, Takeshi Kikui, and Junichi Takada, Suntory Ltd., Kyoto, Japan

Kyoto Brewery, located in the city where the Kyoto Protocol was adopted at COP3, has been promoting environmental activities based on the $3 \mathrm{R}$ (reduce, reuse, and recycle) concept in order to fulfill its corporate social responsibility by becoming an "eco-brewery" (an eco-friendly brewery) guided by the corporate philosophy "resonating with people and nature." For example, a significant reduction in water consumption has been achieved by constructing a water-reuse system. In the system, relatively clean wastewater used for final rinsing of CIP, rainwater from rooftops, etc. is collected and reused for cooling towers, etc. based on an analytical approach that uses water pinch-technology. In addition, the following measures were taken to reduce water and energy consumption: heat recovery from hot wastewater from the brewhouse, water circulation in the empty can rinser using a microfiltration membrane, and rationalization of the electricity and heat supply system by installing cogeneration systems, etc. Furthermore, a warm-water spray, the temperature of which can be adjusted depending on the dew point in the production area, is used to control the temperature of the filled cans/bottles of beer. As a result, specific water consumption in 2007 was $35.4 \%$ lower than in 1996, and specific energy consumption was $50.0 \%$ lower than in 1990 . Not only reductions in water and energy inputs, but also extensive activities for environmental preservation have recently been developed. The "Zero-Waste Campaign" has been making progress, with the result that waste discharge in 2007 was cut to half of that in 1997, and $100 \%$ recycling has been maintained for by-products and waste since 1998. Carefully managed collection of garbage by type has also been making a contribution to $100 \%$ recycling. Eco-friendly products have also been purchased for $93 \%$ of goods used in the brewery, such as office supplies and daily necessities. Furthermore, environmental activities, such as participation in forest protection programs and environmental exhibitions, periodic clean ups of the streets around the brewery, etc., have been carried out to create a sense of solidarity with neighboring communities, local governments, and adjacent companies.

Yuki Osako graduated from Kyoto University with a master's degree in mechanical engineering and began his career at Suntory Limited, Japan, in 2005. He has promoted a range of environmental activities to reduce water and energy consumption and waste discharge at the Kyoto Brewery by implementing technical improvements in the brewing, packaging, and power supply processes, as well as installation of efficient systems as the energy manager assigned by the 
government. He made a significant contribution to Kyoto Brewery's winning the Prime Minister's Award for those who contributed to the promotion of the $3 R$ s (reduce, reuse, and recycle) in Japan in 2008. He is currently the chief project engineer, managing a number of technical innovations being undertaken at the brewery.

\section{O-36}

Reduction of CIP water by use of conductivity probes and reclaim water systems

Presenter: Bryan Sullivan, Anheuser-Busch InBev, Van Nuys, CA

Coauthor(s): Bhanu Jain, Anheuser-Busch InBev, Van Nuys, CA

California is currently in a drought, and all industries must look at their water usage across the state. A large water use outside the brewing process is the CIP of process vessels and lines. The reclaim of the final rinse of CIP loops can be used for the pre-rinse on the next CIP cycle. Installation of conductivity probes in the return header can be used to detect the caustic/water interface, optimize final rinse times, and eliminate manual final rinse checks. Several rinse cycle times have been reduced by $40 \%$ or more. Also, if conductivity of final rinse water is low, it can be used in various utility operations.

Bryan Sullivan is the process support assistant brewmaster at Anheuser-Busch InBev's Van Nuys brewery. He began his career in Anheuser-Busch's research pilot brewery in St. Louis, MO. He has worked in all brewing areas. Bryan holds a B.S. degree in electrical engineering.

\section{0-37}

Status of the yeast propagation process in breweries and some unanswered questions!

Presenter: Olav Nielsen, Alfa Laval, Soborg, Denmark

Yeast propagation is an old and well-established process in breweries. However, development is constantly going on, and some questions still remain unanswered. The demand for good brewer's yeast can be summarized in the following words: a non-stressed and highly vital and viable yeast that is free from other infecting organisms. The road to this goes over a carefully designed sanitary propagation plant with an aeration aggregate that is able to supply a sufficient and adequate amount of oxygen to all cells in the propagator without causing mechanical stress to the yeast cells and an appropriate propagation wort with the right nutrient composition. No matter how much these parameters are optimized it is, however, still only possible to obtain relatively low cell numbers of around 100-200 million cells/mL equivalent to approximately $2.5-5 \mathrm{~g}$ of dry matter per $\mathrm{L}$ in a traditional batchwise working propagator. This is a very low yield when you consider that the yeast is placed in a $12-18 \%$ sugar solution. With the increasing use of high-gravity brewing and the growing size of breweries, the demand for fresh yeast is growing in both frequency and amount. In order to satisfy this demand and surpass the normally obtainable cell number in the propagator, it is necessary to bypass the Crabtree effect and limit the alcohol formation in the propagator. The only way to do this is by learning from the baking yeast industry and perform the propagation in a fed batch reactor, whereby the sugar concentration is kept low during propagation but not so low that the yeast grows purely aerobically and, therefore, may lose some of its fermentation characteristics. As a result, a kind of hybrid process between traditional brewery propagation and a purely aerobic yeast propagation process seems to be the right solution. The feasibility of this process is discussed.

Olav Nielsen was born in 1951 and graduated from the Technical University of Denmark with an MS. degree in biochemical engineering. Olav worked for many years in other bioengineering fields before joining Scandi Brew in 1996. In Alfa Laval Scandi Brew he holds a position as application engineering manager for yeast, which is a core product of the company. His work has concentrated on developing aeration aggregates for yeast propagation plants and mixers for yeast storage plants, with a focus on efficiency and low stress conditions. Olav's earlier work involved propagation tests verifying the influence of the Crabtree effect on yeast propagation and investigating measurable stress as a result of mechanical impact on propagated yeast caused by agitation and aeration. His previous work has been published at IGB 2003 in Livingstone, EBC 2003 in Dublin, 4th BYFPC in 2003 in Oxford, WBC 2004 in San Diego, and WBC 2008 in Honolulu. Olav's planned work involves the use of the fedbatch process during propagation and further research into minimizing vitality and viability loss during storage.

\section{O-38}

Applications for yeast as an inert carrier

Presenter: Craig Duckham, Cara Technology Limited, Leatherhead, UK

Coauthor(s): Bill Simpson, Cara Technology Limited, Leatherhead, UK

As the agent of fermentation, yeast and yeast technology are areas with which brewers are well acquainted. But, there is more to yeast. In the last decade considerable progress has been made in the exploitation of yeast as an inert carrier of small molecules. While commercial products consisting of mineral-enriched (particularly zinc-enriched) yeast cells have been used by brewers for some time, the potential for encapsulating other chemicals in yeast is less widely known. Materials that can be encapsulated within dead yeast include flavors, antioxidants, and vitamins. The benefits of encapsulation can include dramatic improvements in the stability of encapsulated molecules against heat, light, and moisture. The products formed as a result of encapsulation can be stored dry. Volatile and often flammable flavors can be handled more easily and shipped and stored with few restrictions. Yeast is a natural alternative to other encapsulation materials and offers unique performance benefits. A number of encapsulation technologies using yeast have been developed and refined, many of which are protected by patents. In some cases, materials can be stabilized in yeast at levels as high as $45 \%$ by weight of the powdered or granulated end product. In this paper, the potential for application of these yeast encapsulation technologies is critically evaluated with respect to their manufacture and use in beverage systems to improve flavor, flavor stability, appearance, and nutritional value. Potential opportunities are explored, and aspects related to legal issues and labeling are discussed. The potential use of waste brewery yeast for encapsulation of materials for nonfood applications (such as pesticides, herbicides, antibacterials, antifungals, essential oils, etc.) is also discussed. 
Craig Duckham is a specialist in the industrial application of yeasts. He joined Cara Technology Limited as director of operations and development in 2009. In this role he has responsibility for the company's pure yeast culture development and manufacturing operations in the United Kingdom and Denmark. He is responsible for Cara's collection of more than 700 industrial brewing yeast strains. From 2002 to 2008 Craig worked for Micap plc, in the end as technical director. The Micap business was focused on nanoencapsulation of chemicals, including flavors, within yeast. Prior to Micap he spent four years as principal development scientist with Thames Water plc. Following completion of his Ph.D. degree at Nottingham University, he carried out postdoctoral work at the Universities of Lancaster and Reading in the United Kingdom. Craig has published more than 30 peerreviewed papers, patents, and book chapters.

\section{O-39}

\section{A rational approach to yeast strain selection in product} development

Presenter: Bill Simpson, Cara Technology Limited, Leatherhead, UK

Coauthor(s): Chris Giles, Hilary Flockhart, and Craig Duckham, Cara Technology Limited, Leatherhead, UK

Up until the first commercial application of yeast "clones" to make beer in 1883, yeasts were recycled from one fermentation to another, often over centuries. For example, if a yeast culture failed due to microbiological contamination, a replacement culture was obtained from another, usually local, brewery. Thus, in many ways, the year 1883 represents a significant landmark for brewing: the year in which the biodiversity of the yeasts used to make beer first came under threat. Since that time, hand in hand with the rise of multinational brewery groups, national brewers, and independent breweries, which all rely on centralized supplies of yeast cultures, the number of yeast strains used to make the world's beer supply has declined. It is estimated that more than $40 \%$ of the world's beer (including lagers, ales, stouts, and even wheat beers) is fermented and/or re-fermented with one single strain of lager yeast. This change has simplified things for the brewer. Handling multiple yeast strains in a single brewery can be demanding, and cross-contamination of one culture with another is an ever-present risk. But, such simplicity has a cost. Beers that have been made with the same yeast have to rely on differences in malt, adjuncts, hops, water, and process parameters (such as the amount of each material and the temperature and time of each process step) for their distinctiveness. By homogenizing the yeast supply, it could be argued that brewers are missing an important color from their brewing palate. In this paper we will discuss how the current situation can be resolved. Considering the processes involved in developing a new product, we will look at the choices to be made in terms of raw materials, yeast strain, production processes, and product positioning. We will explore how genetic, microbiological, and biochemical information on individual yeast strains can be married to multi-variate statistical sensory analysis tools, including principal component analysis and internal preference mapping. Our aim is to show how rational selection of yeast strains can be aligned to systematic product and process design to create highly targeted products that carry a greater chance of commercial success in the marketplace.
Bill Simpson joined Scottish brewer Tennent Caledonian Breweries in 1977 as a trainee microbiologist. Studying parttime he gained a first-class honors degree in microbiology and a lot of brewery experience before embarking on a nine-year program of research with the Brewing Research Foundation $(B R F)$ in England. During that time he published extensively in areas such as flavor chemistry, brewery microbiology, and yeast. He rose to the position of principal scientist and head of fermentation before leaving BRF in 1995 to start two companies-Cara Technology and FlavorActiV. In addition to his ongoing research in the areas of beer flavor chemistry, sensory science, and yeast, Bill consults for a number of international brewery groups, with particular emphasis on process problem solving. He won the Institute of Brewing \& Distilling's (IBD's) Cambridge Prize for Brewing Research for his work on hop bitter acids and beer spoilage bacteria in 1991 and has published more than 100 scientific papers, books, and patents on brewing technology. Bill is a Fellow of the IBD and a member of the editorial board of the Journal of the American Society of Brewing Chemists.

\section{O-40}

Active dry yeast-Why should brewers use it? Presenter: Sylvie Van Zandycke, Lallemand Inc., Montreal, QC, Canada

Recently, dry-yeast producers have focused time and effort on manufacturing a product that is consistent and reliable. A significant amount of research is currently being undertaken to increase our understanding of the drying and rehydration processes and to ensure that yeast cells are protected from stress factors that could lead to cell damage. As a consequence, the quality of brewer's dry yeast has improved significantly, and it currently offers an attractive alternative to pitchable liquid yeast. This presentation will focus on the dry-yeast production process, rehydration and possible applications. During production of dry yeast, a series of steps aimed at preparing the yeast and its membrane against the effects of desiccation are performed. The yeast produced is then rigorously tested for microbiological content, genetic integrity, viability, and vitality, as well as fermentation performance. Once the product reaches the individual brewer, the brewer is responsible for rehydration of the yeast. This critical step is necessary for the yeast to slowly re-adapt to a liquid environment without damaging its membranes. Particular attention should be given to the manufacturer's instructions, as precautions should be taken in terms of rehydration media, temperature, mixing, and time of rehydration to ensure optimum yeast condition. Dry yeast can then be used for a number of applications, including primary fermentation, bottle conditioning, emergency back-up stocks, propagation starters, and special and one-off brews. Each of these applications will be reviewed in detail to highlight some of the advantages of using dry yeast.

Sylvie Van Zandycke studied biochemical engineering and fermentation at the Institute Meurice (Brussels, Belgium) and completed her degree in September 1996. During that time, she obtained an Erasmus studentship for a 6-month project on brewing yeast cell aging at Oxford Brookes University. She obtained her Ph.D. degree on oxidative stress and aging in Saccharomyces cerevisiae in July 2000 at Oxford Brookes University. From March 2000, Sylvie was employed as project 
manager for SMART Brewing Services. She was involved in contract research, microbiological analysis, and development of methods and kits for the brewing industry. She also took part in organizing international courses, symposia, and congresses for the brewing industry. In 2004 Sylvie left the United Kingdom for Canada and accepted a post at Lallemand Inc. as project manager for their Genetic Identification Laboratory. She was involved with both yeast and bacteria $Q C$ and $R \& D$, and her main focus in research was developing new methods for microorganism identification and characterization, as well as detection of contaminants in alcohol production processes. Since February 2007, Sylvie has held the position of brewing fermentation manager for Lallemand to service and support the brewing industry worldwide.

\section{Poster Presentations}

\section{P-41}

\section{Strecker aldehydes production during beer aging}

Presenter: Morio Fukui, Kirin Brewery Co., Ltd., Yokohama, Japan

Coauthor(s): Mari Sakurai, Yoko Yasuda, Osamu Ogane, Toshiya Ito, Takeo Imai, Yutaka Ogawa, and Tomohiko Ichii, Kirin Brewery Co., Ltd., Yokohama, Japan

Strecker aldehydes, derived from the amino-carbonyl reaction and the following Strecker degradation of the amino acids, are considered to be important constituents of an aged flavor in beer, as well as lipid oxidation products. Because heat accelerates those reactions, lower thermal loads during the wort production processes are considered to be effective to reduce Strecker aldehydes in beer. In this study, we examined the potential of Strecker degradation in bottled beer, as well as the effect of the wort boiling and clarification processes and concluded that the Strecker aldehydes that increased in bottled beer during storage were derived from the following two sources: 1) Strecker degradation during the wort boiling and clarification processes (85\%); and 2) Strecker degradation of the remaining amino acids in bottled beer (15\%). Furthermore, it is also clear that the proportion depends on the remaining amounts of each amino acid in the bottle and the reactivity to Strecker degradation. From these results, we believe that the Strecker aldehydes produced during wort production may form a type of complex, remain in bottled beer, and subsequently be released under the influence of storage conditions such as temperature, $\mathrm{pH}$, and so forth. This concept has much in common with the issues of trans-2-nonenal, as the key factor in flavor deterioration. Therefore, considering effective ways to reduce the production of Strecker aldehydes regardless of the storage conditions, we believe it is important to repress Strecker degradation during the wort boiling and clarification processes and to reduce the amounts of Strecker aldehydes that pass into the final product. In the former case, reducing excess thermal load appears to be one very effective method. Recent innovations in wort boiling equipment have made this method possible during the actual brewing process. In the latter case, our test results indicate that the use of high-vitality yeasts can be effective. We anticipate great progress will be made in this line of research in the future.

Morio Fukui works as a researcher responsible for beer flavor stability at the Research Laboratories for Brewing of Kirin Brewery Co., Ltd. He graduated from the University of Tokyo,
Japan, where he received an M.Eng. degree. In 2005 he joined Kirin Brewery in his present position.

P-42

Reducing odor emissions by treating brewhouse vapors with ionized air

Presenter: Udo Funk, GEA Process Engineering Inc., Hudson, WI

Coauthor(s): Alexander Hofmann and Rudolf Michel, GEA

Brewery Systems GmbH, Kitzingen, Germany

Breweries all over the world are faced with the following problem: brewing facilities that were once planned and built on the outskirts of a city have become surrounded by residential buildings over the years. Very often, odor emissions from wort boiling are perceived as unpleasant by many residents, particularly if vapors are emitted through the vapor stack throughout the whole year. When residents complain, the brewery has to take action and find a remedy. So far, most measures for the reduction of odor emissions have required extensive upgrades and high maintenance efforts. The aim of our research project was to find a simple and cost-effective method for lowering the odor emissions from brewhouse vapors significantly. A joint project of Vereinsbrauerei Apolda, company Luwatec, and GEA Brewery Systems investigated a new method that oxidizes and neutralizes vapor emissions. The newly developed ionization system was installed behind the vapor condenser of the wort kettle. To determine the degree of odor removal achieved by such an ionization system, an olfactometric analysis of the brewhouse vapors and a measurement of the total organic carbon (TOC) figures have been carried out by the German TÜV. With the installation of an ionization system at Vereinbrauerei Apolda, the original intensity of odor emissions from wort boiling could be reduced by at least $70 \%$. This was confirmed by the independent TÜV report. Since the installation has been in operation, the brewery reports that there have been no odor nuisance complaints from surrounding residents. With its low energy consumption of only $1.5 \mathrm{~kW}$, fully automatic operation, and fewer maintenance requirements, the ionization system at Vereinsbrauerei Apolda could meet the objective to find a simple, cost-effective solution to reduce odor emissions from brewhouse vapors. The ionization system clearly reduces odor emissions from brewhouse vapors similar to those conditions found in nature. Flavor-active hydrocarbons are transformed into carbon dioxide and water by undergoing oxidation reactions in the presence of activated oxygen. This process is well known as "cold combustion," which also results in the "clean air" impression after heavy rain falls in combination with thunderstorms.

Udo Funk started his brewing career with an apprenticeship in the Henninger Brau, (Frankfurt, Germany) and graduated as a brewery engineer from the Technical University

Munich/Weihenstephan in 1994. As a commissioning engineer, process and project manager, head of commissioning, and sales engineer, he worked in different companies who supply the brewery industry. In 2003 Udo joined Huppmann AG as a project manager for turnkey breweries and sales manager, Latin America. After Huppmann was purchased by GEA, he was offered the sales position responsible for the North American market and now lives with his family in St. Paul, $M N$. Udo is currently the sales manager responsible for the North American market for GEA Brewery Systems. In this 
function, he represents Huppmann $\mathrm{GmbH}$, Tuchenhagen Brewery Systems GmbH, GEA Diessel GmbH, and GEA Process Engineering Inc.

\section{P-43}

Techniques for the production of world-class lagers using two-vessel brew systems

Presenter: Marty Velas, Copper Cellar Corp., Knoxville, TN

The reasons that most brewpubs do not make authentic lagers beers are that lager brewing requires more equipment at startup, takes longer to process, and the know-how for the lager process is not as prevalent as that for ale production. Coming from a lager-brewing background and finding myself involved in pub brewing, I have over the years developed some techniques that have enabled the production of authentictasting lager beer on equipment with limited sophistication. Most brewpub systems are composed of two vessels that are sometimes mounted on a skid. These are typically a mash/lauter combo tank and a kettle/whirlpool. These are not ideal for decoction or even step mash, but thanks to the high level of modification of available malts, this can be dealt with. Acidification, if called for, can be accomplished through the use of acidulated malt or acid additions in the mash. Providing a source of softened water for sparging can reduce extraction of astringent polyphenols substantially. This is vital for the production of light lagers and delicate, hoppy pilsners. This can be accomplished with an RO or DI system coupled with a buffer tank. Reducing the sparge water temperature can also have a beneficial effect. Because many of these systems do not have the ability to heat the mash, an abbreviated mash cycle is followed by a cooler sparge/runoff cycle while mashing continues. Subsequently, heating immediately in the kettle to mash-off temperature "locks in" the desired sugar ratio. If fermentation space is tight, larger, multi-batch cylindro-conical tanks are not much wider than single-batch tanks and can be placed in roughly the same footprint, as long as the ceiling height can accommodate the increased height. By brewing 2-3 batches of lager at a time, the cycle time is mitigated by having that much more product in the same footprint. Part of the tank can be processed at 28 days, and the rest allowed to continue aging and settling, when it only gets better. Techniques such as flotation and spunding can also be accomplished with minimum modification. Brewers who choose to accommodate these requirements will be on the leading edge of the continuing demand and discernment of beer-loving patrons in their area.

Marty Velas is the director of brewing operations for Smoky Mountain Breweries of Tennessee. As brewmaster he is responsible for producing hand-crafted lagers and ales at four brewing facilities. Marty has received gold medals at the Great American Beer festival national and at the World Beer Cup international competitions. Marty began brewing in 1978 after a trip to Czechoslovakia exposed him to world-class beer. In 1986, working as an aerospace engineer in his native California, he traded aerospace for a career in professional brewing when he signed on with the first microbrewery in southern California, Alpine Brewing Co. In 1989, he was sent to southern Bavaria to complete a journeyman-ship at the Hofbräuhaus Traunstein. Marty began consulting in 1991, designing breweries and implementing improvements in the factory, while training and fine-tuning in the field. In 1993, while teaching brewing courses at UCLA, Marty was tapped to design an intensive, hands-on, brewer-training program. He directed the American Craft Brewers' Academy until 1996. Marty was instrumental in establishing the first craft brewery in Japan in 1994 (Echigo Landsbrauerei), introducing brewing styles such as bock, stout, pale ale, red ale and Bavarian style Weizen beer.

\section{P-44 \\ Withdrawn}

\section{P-45}

\section{The effective use of propylene glycol-based secondary refrigerants}

Presenter: Kevin Connor, Dow Chemical, Midland, MI

The ability to accurately control temperature throughout the brewing process plays a critical part in producing high-quality beer with desirable and reproducible flavor characteristics. Often a secondary refrigerant, such as propylene glycol, is used along with a non-ozone-depleting primary refrigerant, like ammonia, to provide necessary cooling. The food-grade status of propylene glycol makes it an attractive secondary refrigerant, particularly in the event of accidental spills or leaks, and solutions with water are non-flammable, have a low environmental impact, and provide effective heat transfer down to temperatures as low as $0^{\circ} \mathrm{F}$. When propylene glycol is properly formulated to include suitable corrosion inhibitors, long-term corrosion protection of pipes, pumps, tanks, and chillers is readily achievable. However, poorly formulated or badly neglected propylene glycol-based secondary refrigerants are more corrosive than plain water and can also contribute to other problems, such as a buildup of mineral scales, bio-film fouling, decreased pump performance, and inefficient heat transfer. Most of these problems don't happen over night and, in fact, are not normally noticed until they reach a point where they can affect cooling capacity, which in turn affects production and/or product quality. By then the problem has caused irreversible damage that can only be corrected by shutting down the refrigeration system to replace the fluid and to clean, repair, or replace damaged system components. Avoiding the pitfalls of improper selection and operation of propylene glycol-based secondary refrigerants is not difficult, and it can contribute to lower operating costs and help avoid costly shutdowns. A "how to" guide and review of effective practice for propylene glycol-based secondary refrigerants is presented.

Kevin Connor received his B.S. degree in chemistry from the University of Waterloo (Canada) in 1985. He has worked for The Dow Chemical Company for 24 years and is currently a senior development specialist responsible for technical support of the DOWTHERM and DOWFROST inhibited glycol heat-transfer fluids product line. Kevin has been a member of ASHRAE for the past 10 years and currently serves as a voting member for TC 3.1 Refrigerants and Secondary Coolants. He is married and has two children ages 14 and 16. 


\section{P-46}

The truth about oxygen measurement technologies Presenter: Frank Dunand, Hach Lange, Geneva, Switzerland Coauthor(s): Nicolas Ledermann and Serge Hediger, Hach Lange, Geneva, Switzerland

As all major oxygen analyzer suppliers have released an improved version of their existing products or launched a new product based on optical technology over the past two years, we thought it would be an appropriate time to review the existing technologies from a critical and objective viewpoint. Based on the oxygen measurement experience amassed by Orbisphere over 40 years in the brewing industry, and in both amperometric and optical technologies, we have evaluated the advantages and drawbacks of the most common oxygen sensors from the point of view of a brewer's needs. Critical aspects such as response time, long-term stability, and process condition effects are discussed, as well as the benefits of the latest developments in the oxygen optical sensors.

Frank A. Dunand is the senior product innovation manager at Hach Lange (Ph.D. degree in chemistry, Swiss Federal Institute of Technology, Lausanne, Switzerland; M.S. degree in chemistry, University of Fribourg, Switzerland). He joined Hach Ultra in 2002 as a product manager and was promoted to senior product manager, heading the team managing Orbisphere and Polymetron products. Frank is responsible for product innovation at Hach Lange in Geneva, Switzerland. He has authored 15 technical papers in the analytical chemistry field.

\section{P-47}

Change from a pilot-plant brewery to a competence center of brewing and environment technology

Presenter: Hans-Jörg Menger, Ziemann Ludwigsburg GmbH, Ludwigsburg, Germany

Coauthor(s): Tobias Becher, Ziemann Ludwigsburg GmbH, Ludwigsburg, Germany

The new challenge in the brewing industry is a process technology that is able to operate with low investment and low life-cycle costs and produce high-quality beers. For the supplier, this represents a change in previous standard research and development activity. The previous main research was located in the production plant. The new, but very important field of activity, in R\&D is an exact analysis of the necessary energy and raw material consumption, as well as the analysis and implementation of an energy and resource concept for the brewhouse and entire brewery, that links all consumers in the brewing plant, as well as optimizes operational aspects and corresponding costs. In view of this situation, the Ziemann pilot brewery, built in 2005, has been designed in a completely new way. The area of the pilot plant has been doubled in order to have sufficient space for the equipment and to develop an environmental technology, in addition to the brewhouse technology, especially the no waste concept. This presentation shall give an overview of the new design of the plant, strategic adjustments of the new center of competence, and the first scientific results. New process and energy-saving technologies throughout the entire brewery plant are coming out of the development activity of the new pilot center: water saving due to new cleaning and disinfection system and energy saving due to new process management with new in-line analysis systems, high-performance ceramic recirculation system, and optimization in cooling area.
Hans-Jörg Menger received a Ph.D. degree in natural science in April 2003 from the University of Stuttgart-Hohenheim, Germany. He began an apprenticeship as a brewer and maltster in 1985. In 1990 he began studying food technology at the University of Stuttgart-Hohenheim, Germany. He began employment with Ziemann Ludwigsburg GmbH, Germany, in January 1998 in the Technology Department. Since April 2000 he has been responsible for the patent resort, and in July 2003 he was named head of $R \& D$, Technology \& Patent Division of Ziemann Ludwigsburg GmbH.

\section{P-48}

Porous metal spargers for precise control of carbonation processes

Presenter: Ed Napierski, Mott Corporation, Farmington, CT Coauthor(s): Wald Krause, Mott Corporation, Farmington, CT

Precise control of the carbonation process is possible using sintered porous metal spargers. Fine-bubble propagation from the porous media results in complete absorption of carbon dioxide. Diffusing the gas through the thousands of pores of the porous metal media creates bubbles far smaller and more numerous than drilled pipe or other sparging methods. The result is greater gas contacting the surface area, which reduces the time and volume required to dissolve the gas into the beer. Controlled porosity of the porous metal assures consistent, reliable, and repeatable processing times. Constant monitoring of the process is no longer required. Time management is more efficient due to the "set it and forget it" attribute of the porous metal sparger. Tank applications, with the sparging elements located inside the tank, can be batch or continuous flow. Line applications, with the sparging elements located in the line, can be intrusive (located in-line) or non-intrusive (sparger element is the line).

Edward Napierski, regional sales and technical services engineer, Mott Corporation, Farmington CT, started his career at Mott Corporation as a lab technician in 1971 after graduating from Central Connecticut State University with a B.A. degree in physics. During his 39+ years at Mott, he has gained a wealth of knowledge about the many uses of sintered powder porous media in numerous applications across many industries. Prior to his current position, Ed has held various positions at Mott, including isostatic operator, furnace operator, supervisor of isostatic and powder operations, project engineer (reporting directly to Mr. Mott), process engineer, manufacturing liaison to sales, OEM account manager, chief process engineer, production manager, applications manager, and quality control manager. Ed is a member of the APMI International Metallurgy Institute and was its 1993-1994 Connecticut Section chair. Ed is also a member of SME and ASM.

\section{P-49}

Liquid desiccants for minimum refrigerant charge cooling of breweries

Presenter: Phil Rowland, Niagara Blower Company Coauthor(s): Bill Griffiths, Humidity Control Consulting

Environmental, regulatory, and economic issues are driving interest in the use of refrigeration systems with the smallest possible refrigerant charge. Comfort conditioning systems already have relatively small refrigerant systems that use packaged rooftop equipment or chilled water as a secondary coolant. Process air conditioning systems for food-related 
plants (including meat and poultry processing, all kinds of processed foods production, and brewing) have mainly used distributed refrigeration systems up to the present. These systems inherently have large refrigerant charges, with the associated environmental and regulatory concerns. In addition, distributed refrigeration systems commonly have relatively high maintenance costs associated with refrigeration replenishment and leak control. Food-related applications also typically require air delivery at or below freezing, and control repair and maintenance costs associated with coil defrost cycles become significant. Glycol and halide salt solutions both provide a simple and proven secondary coolant for minimum-charge refrigeration systems operating at temperatures below freezing. With this approach, the refrigerant charge remains in the equipment room, and the secondary coolant is piped to and from the processing rooms. With the use of plate heat exchangers for the evaporator and condenser, the refrigerant charge in these systems can be readily reduced to less than $5 \mathrm{lb} /$ ton of cooling. In most cases, this can reduce the refrigerant charge below the threshold for onerous reporting and regulatory requirements. In addition, health and safety concerns related to the presence of refrigerant in the processing rooms are eliminated. For these applications, liquid desiccant equipment has the additional advantage of providing frost-free cooling of the process air. This completely eliminates the hardware, controls, and complexity required for a defrost cycle and frequently reduces the refrigeration tonnage required by $20 \%$ or more and provides consistent outlet conditions for the process. (Liquid desiccant equipment has the further potential of using the same solution for both the secondary coolant and the desiccant.) The piping, thus, serves the dual purpose of secondary coolant distribution and desiccant distribution. Recovered heat from the condenser side of the refrigeration process can be used to provide part or all of the heat required for desiccant regeneration, further enhancing the overall energy efficiency of the process air cooling system. Liquid desiccant equipment also provides additional benefits in process sanitation by supplying clean, dry air to keep the air distribution system clean and discourage bacteria, virus, and mold growth in the processing area. This presentation describes past use of liquid desiccant technology in brewery applications and future potential use minimum-charge refrigeration system applications.

Phil Rowland is a product manager for Niagara Blower Heat Transfer Solutions (Buffalo, NY). Niagara provides engineered solutions to heat-transfer applications at refinery, process, power, and food and beverage facilities worldwide. Niagara's two major product lines are the Wet Surface Air Cooler (used for cooling and condensing liquids and vapors) and the NoFrost ${ }^{\circledR}$ system (used for air cooling and dehumidification). Phil has 24 years of practical knowledge in the field of engineering and specializes in the design and implementation of No-Frost $\AA$ refrigeration and dehumidification systems for the food and beverage industries.
P-50

Storage vessels: Protect your products from contamination and avoid production downtime by monitoring your storage vessels

Presenter: Lee Zacharczuk, Ross Hartrick (1978) Limited, Gadshill, ON, Canada

Coauthor(s): Guy Zacharczuk, Ross Hartrick (1978) Limited, Gadshill, ON, Canada

Monitoring the distribution of a product begins with what you bring into your plant, i.e., the raw materials/ingredients you use to brew your brands, followed by the quality of water you use. Every plant takes measures in monitoring these vital parts in the brewing process. Once approvals have been met, ingredients are blended. This is the start of transferring valuable product into vessels that are going to storing their products in the highest controlled environment. All storage tanks, whether plastic, stainless-steel, or lined tanks, must be approved to store your products, giving you piece of mind that they are sterile and free of any contamination that could affect the product. Contamination or damage can happen in any type of tank if it is not used or cleaned properly. Contaminations that could occur include aged linings that are past their prime in protection, i.e., years in service, as time goes by many brews pass through tanks, meaning after a brew is complete the vessel needs to be cleaned and sanitized by means of heat or chemical cleaning to give the plant a clean vessel to transfer its next product into. In brewing operations, modern testing equipment can monitor its own process and where changes in the quality come from, i.e., if a vessel is not clean enough the plant needs to clean it better, i.e., a longer cycle or different cleaning solution. Cleaning products and methods should have the lining manufacturer's approval, protecting plants from exceeding lining limitations. Should high unacceptable readings continue, an inspection is needed to find if the vessel has any areas where a tank is not being cleaned properly, from a possible malfunctioning cleaning head or sprinkler (Gama/Tiger) jet, or if the tank has any damage, i.e., mechanical damage from a dropped tool creating a chip on the vessel, exposing mild steel or deep scratches and making it impossible to clean; these areas must be repaired. Lining monitoring, inspection, and maintenance programs are put into place to give plants the highest quality controlled atmospheres. These vital programs will ensure your product and your plant's production will continue to produce successfully without the stress of unnecessary production downtime or contaminated brews. Vessel monitoring, inspection, and maintenance should be among the first steps in assuring cleanliness and quality.

Lee Zacharczuk has been a member of MBAA since 2004 and is a second-generation member following his father Ed Zacharczuk (MBAA member since 1986, founder of the Tank Lining Division of Ross Hartrick (1978) Limited, and owner of the company [since 1978], which has provided tank lining applicator services for breweries since the 1980s). Ed has passed the company to Lee and his brother Guy, who have both been qualified inspectors and applicators in the industry since the early 1990s. Both are now active members of the MBAA District Ontario. Lee has been an active member of the District Ontario Technical Committee since 2005 and the representative for Ross Hartrick (1978) Limited for tank lining across Canada since 2004. 


\section{P-51}

Modern process engineering for fermentation and storage cellars

Presenter: Stefan Epple, Krones AG, Neutraubling, Germany

Based on experience garnered from numerous fermentation and storage cellar projects, Krones has developed a new processing concept for cellars. This paper presents the latest findings and the development of this concept. The result of this work meets the requirements of modern breweries, with a view to achieving optimum product quality and efficiency, while taking long-standing experience and practice into consideration. The new cellar concept is based on a design of separate filling and discharging blocks with double-seat valves. Several tanks can be put on a common pipeline. The aggregate number of tanks can be defined individually. The gas side is achieved fully automatically with double-seat valves or, alternatively, semiautomatically with tilting bends. This concept makes the cellar independent of the number of tanks and the length of pipelines, and as a result, it is more flexible and expandable. The well-arranged and accessible construction facilitates handling and maintenance. Through the use of double-seat valves, directly at the tank outlet, the product content in the uncooled pipes is reduced to a minimum. With regard to product safety, the product lines and CIP lines are separated for leak safety. Discharging pipes on the product side are equipped with a D/A water supply to minimize oxygen uptake and increase product quality. Unlike other proposals relating to modern cellar concepts, Krones delivers a philosophy that holistically fulfills all the conditions encountered in today's brewing industry. Through targeted interconnection of the shortest pipeline routes that can be cleaned before and after production, product and detergent are reduced to a minimum. A loop of the feed and return line also minimizes media mixing, and the effectiveness of the CIP plant is efficiently utilized. Proper cleaning of all pipe lengths, as well as the tank outlet, through back flushing is guaranteed. With the shorter pipeline routes, lower pressure losses on the pressure and suction sides of the pump are also achieved.

Stefan Epple is the regional sales director for Krones Brewery and Beverage Processing Equipment located in Neutraubling, Germany. He is responsible for directing all sales and support activities for the processing group for Western Europe and North America. Stefan has more than

17 years of experience in the brewing and beverage industries. He holds a degree in brewery and beverage technologies from the University of Munchen-Weihenstephan. Prior to joining Krones AG, Stefan held various positions at four breweries in Germany-Stuttgarter Hofbrau AG, Jankes Hausbrauerei, Paulaner Brauerei, $A G$, and Tucher Brau AG.

\section{P-52}

Calculations of extract and gravity relationships using the Balling and related equations

Presenter: Alex Speers, Dalhousie University, Halifax, NS, Canada

Coauthor(s): Anthony Cutaia, Science Source Consulting, Ballwin, MO

Aside from the well-known Balling equation, there exists a number of approximate relationships between the original extract, apparent extract, real extract, and alcohol level, as well as the apparent and real degrees of fermentation. These equations were primarily developed in the 18th century by Balling and Holzner. The constants in these equations were reported to be influenced by the original extract and were developed long before linear regression methods became available in 1896. To test these relations, we have collected six datasets. The first set reports 36 values of original extract, apparent extract, and alcohol; four more datasets contain a total of 496 values of original extract, apparent extract, and alcohol; and finally, a dataset of 586 measurements lists finished beers apparent extract and alcohol values. Using the findings of Hackbarth (WBC 2008), a response surface-type function was developed to predict the real extract from values of original extract and alcohol levels. This prediction was shown to provide good estimates of real extract when compared to the 36-member dataset. Using this collected and calculated data, we report on the utility, accuracy, and precision of the relationships between the original extract, apparent extract, real extract, and alcohol level, as well as the apparent and real degrees of fermentation.

Alex Speers is a professor in the Food Science and Technology program at Dalhousie University, Halifax, NS, Canada. Alex received his graduate education in food science at the University of British Columbia, Vancouver, BC, Canada. At Dalhousie University, he instructs students in brewing science, quality assurance, and food product development. In the past, Alex has been employed in the Quality Assurance Departments of both Labatt and Molson Breweries. His current research interests include various aspects of the brewing process, including fermentability, yeast flocculation, premature yeast flocculation, extract calculations, and the properties of (and problems created by) $\beta$-glucan and arabinoxylan polymers. He has organized and/or presented brewing workshops in China (Changzhou, Qingdao, and Yangzhou; 1997-2005) and recently at brewing conferences in Honolulu, HI; Nashville, TN; San Francisco, CA; and the International Brewers Symposium: Yeast Flocculation, Vitality, \& Viability in Boston, $M A$, in 2009. Alex has spent sabbaticals at CUB/Fosters in Melbourne, Australia, and the Columbia Brewing Company in Creston, BC. On occasion he instructs at the Siebel Institute of Technology. Alex belongs to several professional societies and is a member of the editorial boards of Food Research International, the Journal of the American Society of Brewing Chemists, and the Journal of the Institute of Brewing. He also currently chairs the Editorial Board of the Master Brewers Association of the Americas. He has published or presented more than 100 papers.

\section{P-53}

A new way to brew alcohol-free beer

Presenter: Guangtian Zhou, Shandong Institute of Light Industry, Jinan, China

Coauthor(s): Zongcui Yue, Shandong Institute of Light Industry, Jinan, China; Wenjuan Zhao, Jinan Beer Group, Jinan, China; Shanshan Li, Shandong Institute of Light Industry, Jinan, China; Leo Thamm, Freiburg, Germany

This paper describes a new way to brew alcohol-free beer that simplifies the process of producing alcohol-free beer with excellent quality; the method is especially suitable for small and regional breweries. The new production process includes mashing, limited fermentation, vacuum distillation, and preparation of alcohol-free beer. A wort $\left(11^{\circ} \mathrm{P}\right)$ is prepared with $70 \%$ barley malts and $30 \%$ wheat malts as the raw 
material using an infusion mashing method. Then, the wort is filtered through the lauter tun. After boiling, hopping, and clarification, the wort is cooled in preparation for the addition of top-fermenting yeast No. 303 and subsequent fermentation at $17^{\circ} \mathrm{C}$. Fermentation begins when the cooled wort is placed in the fermenters. As soon as fermentable extract of fermented medium is decreased about $25 \%$, the fermented medium is quickly cooled to $0^{\circ} \mathrm{C}$ and is stored for 2 days. Then, the yeast is separated from the "young beer." After that, the young beer is pumped into the continuous vacuum distillator to remove alcohol and concentrate the young beer. Lastly, the concentrated extract, with a concentration of $60^{\circ} \mathrm{P}$, is obtained. In breweries, the concentrated extract can be used as raw material to produce alcohol-free beer. Desoxydated water and concentrated extract are mixed and put into a storage tank, with a concentration of $4.0^{\circ} \mathrm{P}$ at $1-2^{\circ} \mathrm{C}$ and carbonating with $\mathrm{CO}_{2}$ to $5 \mathrm{~g} / \mathrm{L}$. Then, about $8-10 \%$ normal matured beer with an alcohol level of $4.5-6.0 \%(\mathrm{v} / \mathrm{v})$ is added. Storage for 2-3 days under an appropriate pressure at a low temperature can give the beer its zest. Then, the mellowed beer is filtered and, finally, bottled or canned. The alcohol-free beer obtained is of stable quality and good taste. Top-fermenting yeast used during brewing gives the alcohol-free beer a rich aroma of ester and flavor of fullness. Compared with alcohol-free beer produced in other ways, such as a hot method, reverse osmosis, and limited fermentation, analysis and sensory evaluation showed that this alcohol-free beer not only has the characteristics of a normal beer, but also has excellent taste and a good stability. At present, several breweries in China have produced and sold this kind of alcohol-free beer, and in addition, a plant has prepared the concentrated extract for alcohol-free beer.

Guangtian Zhou is a professor in bioengineering and director of the China-Germany Brewing Technical Service Center in the Shandong Institute of Light Industry. Guangtian received his B.S. degree in bioengineering from Shandong Institute of Light Industry in Jinan, China. He worked in the Jinan Beer Group from 1982 to 1987 as a brewer. From 1987 to 1988, he studied at Doemens Brewing Akademie in Munich, Germany. Then, he worked in the Jinan Beer Group as a chief engineer. Since 1994, Guangtian has been working in the Shandong Institute of Light Industry as a professor. He is now the director of the China-Germany Brewing Technical Service Center. Guangtian is also an editor of China Brewing, a wellknown journal in China, and a council member of the Microorganism Association of Shandong, China.

\section{P-54}

\section{Moved to O-32}

\section{P-55}

Comparative barley and malting quality parameters for recent two-row and six-row malting barley varieties registered in Canada

Presenter: Michael Brophy, Brewing and Malting Barley

Research Institute, Winnipeg, MB, Canada

Coauthor(s): Michael Edney, Canadian Grain Commission, Winnipeg, MB, Canada

Malting barley varieties are registered in Canada following rigorous testing of samples of selectable quality from replicated sites grown across the provinces of Manitoba, Saskatchewan, and Alberta. Cooperative test sites are grown in 20 locations across these provinces, and samples from sites with acceptable quality are analyzed and compared to check varieties in controlled micromalting facilities at the Canadian Grain Commission's (CGC's) Grain Research Laboratory (GRL) in Winnipeg, MB. Promising lines from the first year of cooperative tests are also entered in collaborative tests on larger sites, which are coordinated by the Brewing and Malting Barley Research Institute (BMBRI). Samples from two years of collaborative tests are also submitted for barley and malting analysis and compared to current check varieties. Data from these cooperative and collaborative tests are evaluated by expert committees when recommending varieties for registration based on merit relative to check varieties. Over the past eight years, 15 new two-row and 14 new six-row malting barley lines have been recommended for variety registration in Canada. Comparative data for some of these varieties relative to each other and to checks are presented and graphed. Newdale, CDC Meredith, CDC Reserve, Bentley, CDC Landis, and CDC Polarstar are some of the newer two-row varieties compared to checks, including AC Metcalfe. Tradition, CDC Clyde, CDC Kamsack, CDC Mayfair, Stellar$\mathrm{ND}$, and Celebration are some of the six-row varieties compared to checks, including Legacy. The data show that there is now a portfolio of newer varieties available that fit within the quality parameters of existing mainstream commercially grown and marketed varieties in Canada but with improved agronomic and quality characteristics in some cases. Improved agronomic yield, lower barley and malt protein, higher extract, better balance of modification, and low-moderate-high enzyme characteristics are identified for particular two-row varieties. The newer six-row varieties are also compared for agronomic yield and the protein, extract, and enzyme ranges normally required by major end users. This information provides a basis for customers and marketers to identify varieties of interest and to undertake further market development and commercial testing.

Michael Brophy's tenure as president and CEO at the Brewing and Malting Barley Research Institute (BMBRI) began in August 2008. Michael holds master (crops) and bachelor of agricultural science degrees from University College, Dublin, Ireland. His experience in research and development within the Canadian malting barley industry spans more than 15 years. He was senior manager of barley and malting barley research and Product Department activities at the Canadian Wheat Board (CWB) from 1995 to 2008. He was the CWB's international malting barley market analyst from 1993 to 1995. Prior to coming to Canada in 1992, Michael worked with the Irish Farmers Association's Grains and Arable Crops Divisions, which included responsibility for directing research projects and grower supply contracts for malting barley. Michael has been a member of MBAA since 1996 and has been an active member and past chair of the Winnipeg Chapter of MBAA District Western Canada.

\section{P-56}

Colorful wheat beers-Technology for Hefeweizen with different taste and aroma profiles

Presenter: Jens Voigt, Technische Universität München, Weihenstephan, Germany

Coauthor(s): Andreas Richter, Weyermann Specialty Malting, Bamberg, Germany

The production of wheat beers can vary widely in color and aromatic profiles. This paper shows comparative methods for 
the technology in producing darker colored wheat beers made from either a major portion of dark wheat malt only or pale wheat malt with the addition of intensely colored portions of Carawheat ${ }^{\circledR}$ malt. The influence on the character of the final beer with regard to taste, flavor stability, foam formation, and other quality parameters is described. While the color itself can be formulated to a similar level, the different additions and technology of wheat malt show significant and typical differences. Brewing process technology and fermentation were kept similar in order to emphasize the differences in beer character. The use of different malt characters results in distinct typical flavor characteristics and properties. The work shows that there is a great variety of options to create wheat beers of different characters by choosing different specialty raw materials.

Jens Voigt received a diploma engineer (M.S.) degree in brewing and beverage technology from TU MünchenWeihenstephan in 1985. He started his career with A. Steinecker GmbH, Freising, Germany, as a technical engineer in brewhouse and fermentation and filtration equipment. He held sales and product and manager positions with Steinecker until 1995. From 1988 to 1992 he worked on his doctorate in brewing technology on beer foam from Weihenstephan (Professor Narziß). In 1996 he joined Doemens Brewing School in Munich, Germany, as managing director. In late 1997 he joined Heinrich Huppmann GmbH, Kitzingen, Germany, as key account manager for brewery equipment and was managing director of brewmaxx, a supplier of software solutions for the brewing industry. Since early 2004 he has been a research associate with Professor Karl Sommer at Lehrstuhl für Maschinen- und Apparatekunde (Chair for Mechanical Engineering and Process Technology) at the WZW (Wissenschaftszentrum Weihenstephan), Center of Life Science, Weihenstephan, Germany, working on brewing process technology issues. He is a member of the MBAA and IBD, the editorial board of the Journal of the Institute of Brewing, London (JIB), and the MBAA Global Emerging Issues Committee. His work group was recently awarded the EON Award for environment.

\section{P-57}

\section{The farm bill and craft beer}

Presenter: Hugh Burns, Virginia Brewers Guild

The 2008 Farm Bill and its commodity subsidies and farm policies have an impact on citizens and consumers in general and a particular impact on beer brewers who either use subsidized commodities or ingredients in their beers that compete acre for acre against subsidized crops. This paper looks at the practical effects of the farm bill and subsidized agriculture for commodities used in beer, as well as subsidized crops used as ingredients for bio-fuels across the European Union and the Americas, particularly the United States. Considerations are addressed for craft beer brewers who don't use subsidized ingredients and its competitive relevance for craft brewers in the overall beer market.

Hugh Burns founded Williamsburg Brewing Company in Williamsburg, VA, in 1995 and served as its brewer and manager until 2005. Hugh earned a B.S. degree in biology from the University of Scranton in Scranton, PA, in 1981. He served in the U.S. Air Force as a fighter pilot and officer, flying F-4 "Phantoms" and F-117A "Nighthawks" from 1982 to
1995. He is a graduate of the USAF Fighter Weapons Instructor Course (TOPGUN). He has authored and coauthored works on instructional techniques and fighter weapons employment and tactics, as well as papers on brewing history, yeast management, and beer packaging. In 1991 Hugh began home brewing as a hobby and came full circle with his microbiology and biochemistry education roots. Now his efforts are divided among flying airplanes, research and writing, and brewing tasty beer. His first love remains his wife and six children. His second love is making hand-crafted beer.

\section{P-58}

Sustainable brewing solutions-An outlook

Presenter: Roy Johnson, Norit Haffmans, Rockford, IL

Waste at a brewery comes in various forms and amounts, with energy and waste accounting for 3-8\% of the total productions costs. Water that enters a brewery is only utilized at a $30 \%$ rate, with the rest being sent out as effluent. Solid-waste losses can be better utilized for up to a 5\% savings, and energy usage can be cut in half. It is clear that sustainable solutions in the brewery are a delicate balance between financial aspects on the one hand and environmental aspects on the other. This paper investigates opportunities for sustainable solutions that minimize the use of water, energy, and raw materials in modern breweries, while simultaneously lowering the solidwaste stream by over $40 \%$. For example, by integrating membrane solutions into the four water streams of a brewery, it is possible to reduce water use to $1.6 \mathrm{hL}$ of water per $1 \mathrm{hL}$ of beer produced. With additional polishing steps $\left(\mathrm{ClO}_{2}\right.$, GAC, or UV), water re-use of more than $57 \%$ can be achieved. Using membranes during bright-beer filtration can lower the solidwaste stream of a brewery by more than $40 \%$ and completely eliminate DE from the brewing process. Optimizations such as effective heat recovery, efficient $\mathrm{CO}_{2}$ recovery, and the introduction of continuous brewing can reduce energy usage by $50 \%$ compared to the industry average. The paper compares industry figures with the numbers of the leading sustainable breweries and proposes several sustainable opportunities in the brewing field.

Roy Johnson began his career with Miller Brewing Company at the Fulton, NY, brewery in 1983 as a QA packaging analyst. He transferred to Miller's Ft. Worth, TX, brewery as a $Q A$ packaging/product supervisor in 1987. In 1990, Roy moved into the Ft. Worth Brewing Department, where he worked in the brewing, fermentation, aging, and package release areas as a brewing supervisor. Roy was later transferred to Miller's Trenton, OH, brewery in 1994, where he was a brewing area team manager until 1995. In 1995, Roy accepted a position with The PQ Corporation as a national account manager, handling beer stabilization sales to key brewing accounts in North America. Early in 2006, Roy joined Haffmans North America as their sales manager for quality control instrumentation and units. Roy graduated from Pennsylvania State University in 1982 with a B.S. degree in food science and a business emphasis. He obtained an MBA from the University of Texas in Arlington in 1994. Roy is active in MBAA as the current president and $B O G$ representative for District Cincinnati. He is also a past chair of the MBAA Membership Committee. 
P-59

Withdrawn

\section{P-60}

Withdrawn

\section{P-61}

Supplier knowledge transfer equals value transfer Presenter: Arjen van Zeijst, Haffmans BV, Venlo, The Netherlands

Purchasing goods and/or services is a daily part of doing business. Unfortunately, practice shows that in case of emergency or malfunction the operator too often depends on the supplier to solve their problems. As a result, valuable time and money is lost, because the operator is not able to analyze and solve the situation independently. A knowledge transfer program (KTP), however, can make a difference in the daily operation of processes. Training operational and technical people on more than just how to operate the equipment can shorten troubleshooting and problem-solving time. Subjects such as theoretical principles, basic maintenance and service, and training on best practices will enable users to become masters of the equipment. Being more functional, effective, and efficient in operating the equipment is the key objective of a KTP, and an assessment program at the end of the KTP should validate the acquired knowledge level and confirm the aptitude of the operator. This paper shows how to transfer knowledge from the supplier to the equipment operators.

Arjen van Zeijst studied electrical engineering at HTS Venlo, finishing in 1996. Arjen worked for a PVD coating machine manufacturer until 2008 in the following areas: process control engineer, project engineer, head process control department, and international sales manager. Arjen joined Haffmans BV as product/area manager in 2008 and is responsible for quality control equipment in the Americas.

\section{P-62}

Moved to O-38

\section{P-63}

Withdrawn 